\title{
CRITICAL AND SUBCRITICAL NEA BENCHMARK POSSIBILITIES FOR MEASUREMENTS AT ORCEF AND OTHER US DOE FACILITIES
}

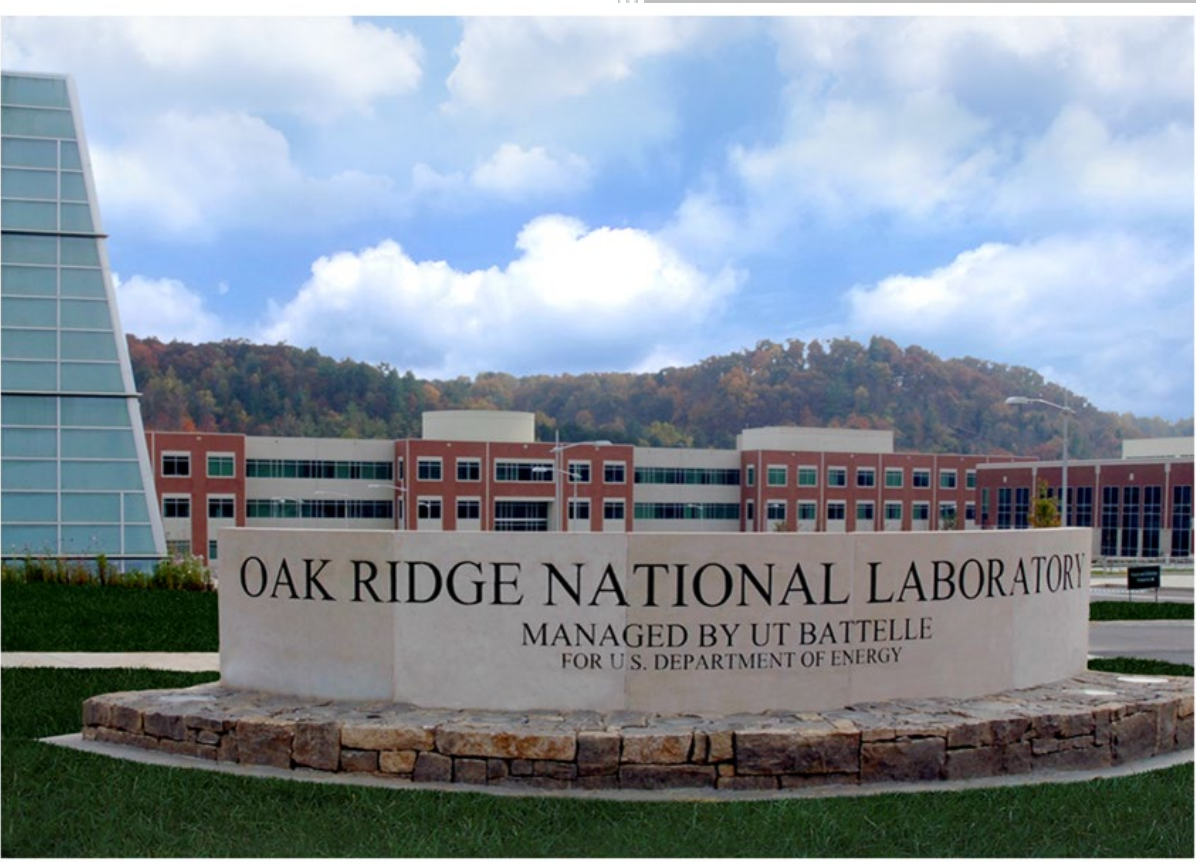

MANAGED BY UT BATTELLE

John T. Mihalczo

Approved for public release. Distribution is unlimited.

June 2019 


\title{
DOCUMENT AVAILABILITY
}

Reports produced after January 1, 1996, are generally available free via US Department of Energy (DOE) SciTech Connect.

Website www.osti.gov

Reports produced before January 1, 1996, may be purchased by members of the public from the following source:

\author{
National Technical Information Service \\ 5285 Port Royal Road \\ Springfield, VA 22161 \\ Telephone 703-605-6000 (1-800-553-6847) \\ TDD 703-487-4639 \\ Fax 703-605-6900 \\ E-mail info@ntis.gov \\ Website http://classic.ntis.gov/
}

Reports are available to DOE employees, DOE contractors, Energy Technology Data Exchange representatives, and International Nuclear Information System representatives from the following source:

Office of Scientific and Technical Information

PO Box 62

Oak Ridge, TN 37831

Telephone 865-576-8401

Fax 865-576-5728

E-mail reports@osti.gov

Website http://www.osti.gov/contact.html

This report was prepared as an account of work sponsored by an
agency of the United States Government. Neither the United States
Government nor any agency thereof, nor any of their employees, makes
any warranty, express or implied, or assumes any legal liability or
responsibility for the accuracy, completeness, or usefulness of any
information, apparatus, product, or process disclosed, or represents that
its use would not infringe privately owned rights. Reference herein to
any specific commercial product, process, or service by trade name,
trademark, manufacturer, or otherwise, does not necessarily constitute
or imply its endorsement, recommendation, or favoring by the United
States Government or any agency thereof. The views and opinions of
authors expressed herein do not necessarily state or reflect those of the
United States Government or any agency thereof.


ORNL/TM-2019/1188

\title{
Critical and Subcritical Experiment NEA Benchmark Possibilities for Measurements at ORCEF and Other DOE Critical Facilities
}

John T. Mihalczo

Date Published: June 2019

\author{
Prepared by \\ OAK RIDGE NATIONAL LABORATORY \\ Oak Ridge, TN 37831-6283 \\ managed by \\ UT-BATTELLE, LLC \\ for the \\ US DEPARTMENT OF ENERGY \\ under contract DE-AC05-00OR22725
}




\section{CONTENTS}

LIST OF FIGURES $\mathrm{V}$

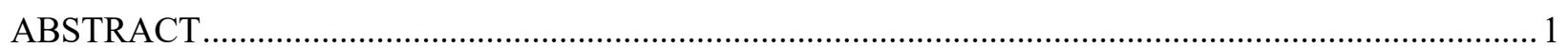

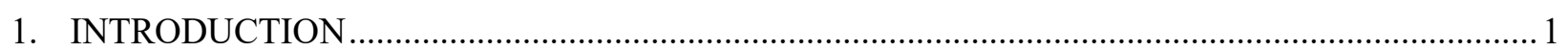

2. BENCHMARK OF CALCULATIONAL METHODS …...............................................................

3. CRITICAL HIGHLY ENRICHED URANIUM-MOLYBDENUM ALLOY ..................................... 3

4. CRITICAL MEASUREMENTS WITH TWO INTERACTING 7-IN.-DIAMETER HEU URANIUM METAL CYLINDERS

5. CRITICAL MEASUREMENTS WITH TWO 15-IN.-DIAMETER HEU URANIUM METAL

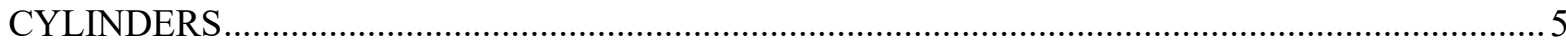

6. CRITICAL MEASUREMENTS WITH HEU METAL CYLINDERS AND ANNULI WITH THICK

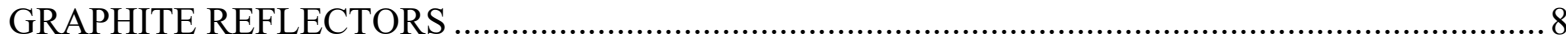

7. CRITICAL EXPERIMENTS WITH 7-IN.-DIAMETER URANIUM METAL CYLINDERs WITH THIN STAINLESS-STEEL REFLECTOR ON TOP AND BOTTOM …....................................

8. CRITICAL MEASUREMENTS WITH THREE INTERACTION 15-IN.-DIAMETER HEU URANIUM METAL CYLINDERS. 10

9. CRITICAL AND SUBCRITICAL MEASUREMENTS WITH JEMIMA PLATES AT ORCEF......12

10. CRITICAL AND SUBCRITICAL MEASUREMENTS FOR THE SHEBA CYLINDRICAL TANK OF URANYL FLUORIDE SOLUTION

11. CRITICAL AND SUBCRITICAL MEASUREMENTS FOR A CYLINDRICAL TANK OF MIXED URANIUM-PLUTONIUM NITRATE SOLUTION

12. BABCOCK AND WILCOX 1983 CRITICAL AND SUBCRITICAL EXPERIMENTS WITH PWR FUEL PINS .16

13. CRITICAL AND SUBCRITICAL MEASUREMENTS FOR A SLAB TANK OF PLUTONIUM NITRATE SOLUTION

14. CRITICAL AND SUBCRITICAL MEASUREMENTS FOR AN ANNULAR TANK OF PLUTONIUM NITRATE SOLUTION

15. CRITICAL AND SUBCRITICAL MEASUREMENT WITH A MOCKUP OF THE SPACE POWER REACTOR-SP-100

16. SUBCRITICAL MEASUREMENT WITH HEU URANYL NITRATE CYLINDRICAL SOLUTION TANK WITH VARYING SOLUTION CONCENTRATIONS.

17. SUBCRITICAL INTERACTING HEU URANIUM METAL SEPARATED BY VARIOUS THICKNESSES OF BOROPLASTER

18. SUBCRITICAL MEASUREMENT WITH TWO INTERACTING URANYL NITRATE SOLUTION TANKS.

19. SUBCRITICAL MEASUREMENT WITH HEU URANYL NITRATE SAFE STORAGE BOTTLES 24

20. SUBCRITICAL MEASUREMENT WITH HIGHLY ENRICHED URANIUM HYDRIDE CYLINDERS. 
21. SUBCRITICAL MEASUREMENTS WITH TWO HIGHLY ENRICHED URANIUM METAL CYLINDERS WITH VARIOUS MATERIALs BETWEEN THEM

22. SUBCRITICAL MEASUREMENTS WITH A HEU CASTING IN A CONCRETE STORAGE VAULT

23. SUBCRITICAL MEASUREMENT WITH UP TO Five ADJACENT UNREFLECTED HEU CASTINGS .29

24. CONCLUSIONS 31

APPENDIX A. NEA AND ISBEP BENCHMARKS. 32

APPENDIX B UNCERTAINTIES IN MATERIALS PROVIDED BY THE Y-12 NSC 34 


\section{LIST OF FIGURES}

Figure 1. Configuration of the system before assembly for systems where the single cylinders could be hand stacked safely (this photo is of 11-in.-diameter cylinders, but this same type configuration was used for these 7-in.-diameter cylinders).

Figure 2. Configuration of the system before assembly for systems where the single cylinders could be hand stacked safely (this photo is of 11-in.-diameter cylinders, but this same type configuration was used for these 15-in.-diameter cylinders).

Figure 3. Configuration of the system before remote assembly for the higher reactivity single cylinders (this photo is of 11-in.-diameter cylinders, but this same type configuration was used for these 15-in.diameter cylinders)......

Figure 4. Configuration of 1-in.-thick bottom and top reflector on 7-in. diameter uranium metal cylinder on the vertical assembly machine at ORCEF (Rossi- $\alpha$ detector in place). 10

Figure 5. Three 15-in.-diameter HEU interacting uranium metal cylinders on the vertical assembly machine at ORCEF. 11

Figure 6. Typical configuration of source and detectors for prompt neutron decay measurements.......... 13

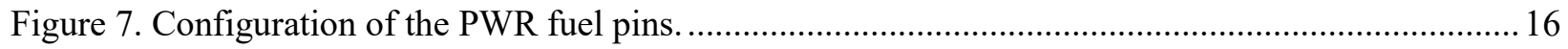

Figure 8. $17 \times 17$ PWR fuel assembly (white circles indicate locations of burnable poison rods)........... 17

Figure 9. Interacting solution tanks with the same fissile concentration with the Cf source in the center of

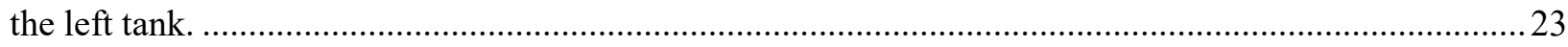

Figure 10. One of six canned 6-in.-diameter HEU metal castings.........................................................2

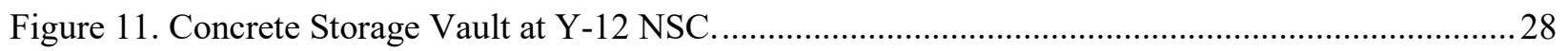

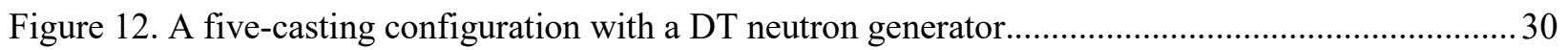





\title{
Critical and Subcritical Experiment NEA Benchmark Possibilities for Measurements at ORCEF and Other DOE Critical Facilities
}

\author{
John T. Mihalczo
}

\begin{abstract}
This report documents a wide variety of critical and subcritical measurements that could be Nuclear Energy Agency (NEA) or International Criticality Safety Benchmark Program (ICSBEP) benchmarks. The experiments are divided into four classes: critical experiments only, critical and subsequent subcritical experiments, subcritical experiments (all performed in critical experiment facilities), and subcritical measurements performed in material balance areas at the Y-12 National Security Complex (NSC) for Y-12 nuclear criticality safety. This report documents the number of critical facility days used to perform the measurements (some measurements have been omitted). Critical and subsequent subcritical measurements in critical facilities at the Oak Ridge National Laboratory Critical Experiments Facility (ORCEF), Los Alamos National Laboratory, Pacific Northwest National Laboratory, and Babcock and Wilcox at Lynchburg, Virginia, used $\sim 350$ operational days of critical facility time; subcritical measurements at ORCEF used 200 operational days; and subcritical measurements in material balance areas of the Y-12 National Security Complex used 350 operational days, many of which were unattended measurements. Because of the high cost of critical facility time and only one facility in the United States currently available for performing these measurements, it is very cost-effective to mine the existing data to produce benchmarks, such as those already in NEA and ICSBEP. Measurements at ORCEF, the material descriptions from Y-12 NSC, and the accuracy of the configurations (based on experience with existing NEA or ICSBEP of ORCEF measurement benchmarks) should result in uncertainties in measured $k_{\text {eff }}$ values lower than \pm 0.001 and may be as low as \pm 0.0002 , thus allowing more accurate comparisons between measurements and calculations and verification of calculations.
\end{abstract}

\section{INTRODUCTION}

Between 1960 and 2000 a wide variety of critical experiments and subcritical experiments were performed at eight different US DOE facilities, many at the Oak Ridge Critical Experiments Facility (ORCEF). One subcritical experiment conducted in 2006 for criticality safety at the Y-12 National Security Complex (NSC) is included. Presently there is only one critical facility operational, and it is at the Nevada Test Site (NTS) operated by Los Alamos National Laboratory (LANL). Some measurements have been documented in ORNL reports and as benchmark experiments in the Nuclear Energy Association (NEA) and International Criticality Safety Benchmark Experiment Program (ICSBEP) data bases. Other measurements are only in 600 word abstracts in Transactions of the American Nuclear Transactions, while others are not documented at all. Those measurements that are already NEA or ICSBEP at Idaho National Laboratory (INL) benchmarks are listed in Appendix A. Because of the highly accurate descriptions of the materials and their configuration for the ORCEF experiments, these measurements have the lowest uncertainty in $\mathrm{k}_{\text {eff }}$ values in the data bases, most below \pm 0.001 , 
some as low as \pm 0.0001 . This allows more accurate verification of calculational methods. The uncertainties in the dimensions, masses, and uranium isotopics measured at the Y-12 NSC are discussed in Appendix B. This report describes measurements that are not in the benchmark data bases. However, the quality of the data and the description of the configurations is good enough to be highly accurate calculational benchmarks for these data bases. In the last few decades the NEA and INCSBEP data bases have been expanded to include subcritical measurements. Some experiments described here were only at delayed criticality. Others started at delayed criticality and then the reactivity was decreased considerably, and still others were only subcritical for a variety of configurations, resulting in $\mathrm{k}_{\mathrm{eff}}$ variations. A variety of measurements were performed including the californium (Cf) source-driven noise analysis for the critical and subcritical configuration. For one measurement at the Y-12 NSC with highly enriched uranium (HEU) metal castings, a time and directionally tagged deuterium-tritium (DT) neutron generator was used as well as a time-tagged Cf neutron source. The brief descriptions in this report state the configuration of the experiments, the materials, the range of subcriticality in some cases, any document references, the days of critical facility time used for the measurements, and recommendation as to what documentation should be completed. These measurements at delayed criticality used about 350 days of critical facility operational days, which would be extremely expensive today even if the materials existed. In addition, the subcritical measurements at ORCEF used 200 days of facility time. Many of the experiments would not be permitted with today's constraints.

The data and descriptions of the materials and configuration are such that these $\mathrm{Cf}$ source-driven noise analysis measurements at delayed criticality and subcritical could be a NEA and ICSBEP benchmarks. In recent years subcritical benchmarks have been added to the NEA and ICSBEP data bases because of the limited number of critical experiments now being performed. In many cases at subcriticality, the neutron spectrum is shifted to higher neutron energies, the effect of neutron reflection changes, and neutron leakage is much greater. The ORCEF experimental logbooks are at ICSBEP.

\section{BENCHMARK OF CALCULATIONAL METHODS}

For delayed critical configurations, various corrections for the support materials were performed for the ORCEF measurements. Thus, calculations could also be compared with configurations with the support structure removed. The calculations of $\mathrm{k}_{\mathrm{eff}}$ for all delayed configurations as built with all support structures can be compared directly with the measurements. These as-built configurations have the lowest uncertainty in measured neutron multiplication factor, $\mathrm{k}_{\mathrm{eff}}$.

For the subcritical configurations, the measured quantities from the $\mathrm{Cf}$ source-driven noise analysis can be calculated directly. These quantities include dependence on the detection efficiency. Thus, the detectors must be included in the calculation. However, there are combinations of the measure quantities such as the ratio of spectral densities or correlation functions that are independent of detection efficiency because the same detection efficiencies appear in the numerator and the denominator of the ratio and thus cancel. The prompt neutron decay constant (a neutron spectrum-dependent quantity) can be obtained from the frequency 
dependence of the cross power spectral densities or the prompt neutron time decay obtained from pulsed neutron or Rossi- $\alpha$ measurements

. An alternate to calculation of directly measured quantities, the source-driven noise analysis measurement data could be interpreted to obtain the subcritical neutron multiplication factor, $\mathrm{k}_{\mathrm{eff}}$. Calculations could be compared with these subcritical multiplication factors obtained from the measurements. However, the multiplication factor inferred from source-driven noise analysis measurements will have larger uncertainties because of the uncertainties in the parameters needed to obtain the subcritical keff values.

Thus, for subcritical measurements the recommended comparison of measurement and calculations is to compare the ratio of measured and calculated spectral densities, the latter of which is proportional to $\left(1-\mathrm{k}_{\mathrm{eff}}\right) / \mathrm{k}_{\mathrm{eff}}$.

\section{CRITICAL HIGHLY ENRICHED URANIUM-MOLYBDENUM ALLOY}

\subsection{Date of experiments and facility time}

These experiments were performed in 1961 between March 16 and June 5 and used 42 operational days of ORCEF critical facility time.

\subsection{Brief description of the measurements}

These delayed critical experiments with $93.2 \mathrm{wt} . \%{ }^{235} \mathrm{U}$ enriched uranium molybdenum (10 wt. \% Mo) alloy were measurements to verify calculational methods for the design of the Health Physics Research Reactor at ORNL. The fissile materials were annular 8-in.-outside diameter, 5-25/32-in.-inside diameter metal plates of thicknesses ranging from $1 / 8$ to 1 in. with some special pie-shaped pieces that were 1/32 in.-thick There were cylindrical alloy plugs (523/32-in.outside diameter) for filling the central holes in the annular plates. The measurements included determination of (1) the critical height of the plates with the center hole filled with UMo alloy, stainless steel, or plexiglas and empty, (2) the effect of the plexiglas reflector, (3) the reactivity of a central void, (4) the spatial distribution of the power density or neutron flux, (5) the reactivity effects of the support structure, and (6) the prompt neutron time decay from pulse neutron measurements.

\subsection{Comments}

These unique experiments are the only critical experiments with highly enriched U-Mo alloy.

\subsection{Documentation}

J. T. Mihalczo, W. E. Kinney, "Experiments and Calculations on Unmoderated Uranium Molybdenum Alloy Critical Assembly” Trans. Am. Nucl. Soc. Vol 4, 1, p 302 (June 1961).

J. T. Mihalczo and W. E. Kinney, "Oak Ridge National Laboratory Fast Burst Reactor Critical Experiments and Calculation”, ORNL/CF-61-8-71, Union Carbide Corp. Nuclear Division, Oak Ridge National Laboratory (Aug 1961). [OSTI \#4822124] 


\subsection{Suggested work}

The data and description of the materials and configuration are such that this could be a NEA and ICSBEP benchmark. It is expected that the uncertainties in the measured $\mathrm{k}_{\text {eff }}$ will be below \pm 0.001 and as low as \pm 0.0002 .

\section{CRITICAL MEASUREMENTS WITH TWO INTERACTING 7-IN.-DIAMETER HEU URANIUM METAL CYLINDERS}

\subsection{Date of experiments and facility time}

These original six experiments were performed in 1963 between April 5 and April 16 and used 6 operational days of ORCEF critical facility time.

\subsection{Brief description of the measurements}

The heights of the 7-in.-diameter height cylinders varied from 2-5/8 to 3-1/4 in. All interacting cylinders were assembled coaxially with their flat faces parallel, and their combined masses varied between 62 and $76 \mathrm{~kg}$ of HEU metal. The spacing between cylinders was the variable that was adjusted to achieve delayed criticality (Figure 1). The experiments were performed in April 1963 and are recorded in ORCEF Logbook E-19 associated with the East cell (ORNL Logbook H00170 or ICSBEP Logbook ????? ).

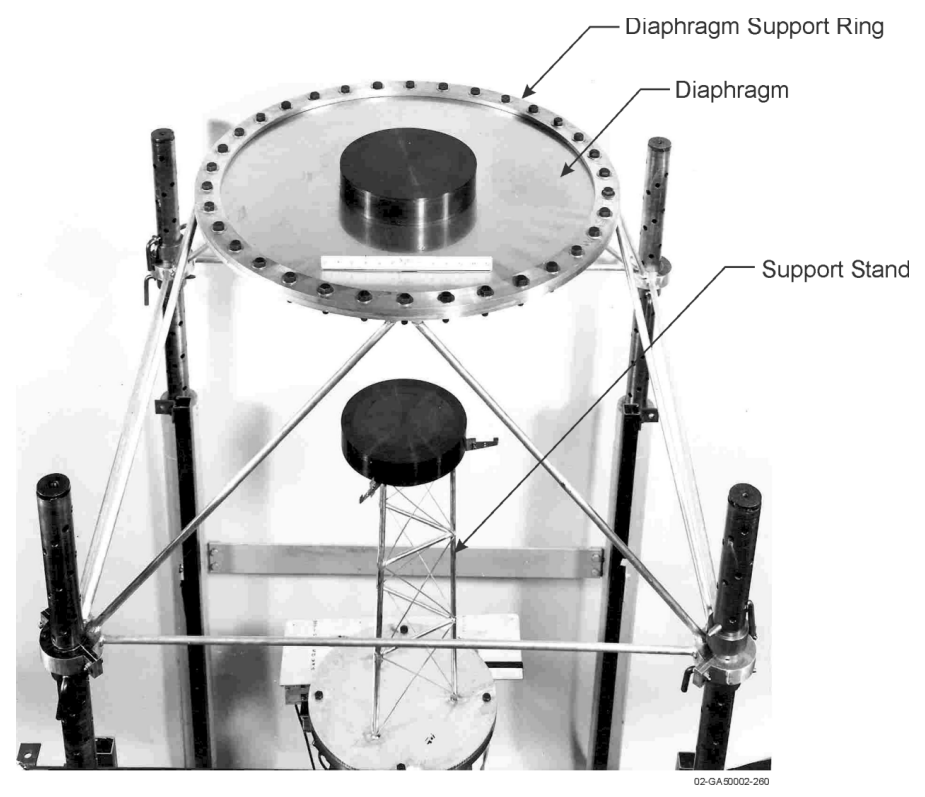

Figure 1. Configuration of the system before assembly for systems where the single cylinders could be hand stacked safely (this photo is of 11-in.-diameter cylinders, but this same type configuration was used for these 7 -in.-diameter cylinders). 


\subsection{Comments}

As the spacing between cylinders increases, the prompt neutron lifetime between fissions increases because the flight time of the neutron between cylinders is significant compared to the neutron lifetime. Because the interaction depends on the travel time between cylinders, the effects of the neutron spectrum are significant, and the agreement between calculations and measurements depends on the correct calculations of the neutron spectrum.

\subsection{Documentation}

Essentially none

\subsection{Suggested work}

The data and descriptions of the materials and configuration are extremely accurate and are such that the measurements at delayed criticality could be a NEA and ICSBEP benchmarks with very low uncertainties in measured $\mathrm{k}_{\text {eff. }}$ A draft on the experimental part of a report for the data benchmark base has been completed. In addition to completing a draft of the experimental work, the calculational modeling and uncertainty analysis along with a comparison with the experiments needs to be completed. Because of the accuracy of Y-12 NSC in characterizing the materials and the accuracy of the experiments, it is expected that the uncertainties in the measured $k_{\text {eff }}$ will be below \pm 0.001 and as low as \pm 0.0002 .

\section{CRITICAL MEASUREMENTS WITH TWO 15-IN.-DIAMETER HEU URANIUM METAL CYLINDERS}

\subsection{Date of experiments and facility time}

These 12 experiments were performed in 1963 between May 16 and May 28, May 31 and June 4, July 31 and Aug 14, and in 1965 between April 13 and May 14. These and their repeated assemblies used $\mathbf{4 4}$ operational days of ORCEF critical facility time.

\subsection{Brief description of the measurements}

In these 12 experiments, the spacing between coaxial uranium $\left(93.14 \mathrm{wt} . \%{ }^{235} \mathrm{U}\right)$ metal cylinders varied from about 0.5 to 52 in., their thicknesses varied from 1.625 to 3.000 in., and the masses of each cylinder varied from 91 to $163 \mathrm{~kg}$. For nine of the experiments, the systems were reassembled and each of the cylinders was composed different uranium metal parts. For one experiment the cylinders were dismantled, the vertical assembly machine was moved to near center of the experimental cell, and the system was reassembled with the exact same parts to measure the effects of location in the room and reproducibility. At the largest spacing, the $\mathrm{k}_{\text {eff }}$ of one of the individual cylinders was over 0.99 . Rossi- $\alpha$ measurements were performed for each of the 12 systems and their repeated configurations, and for some systems the spatial distribution of the fission density was measured. For the largest spacing the distribution of the fission density between cylinders was very sensitive to small differences in the reactivity of each cylinder; thus, 
small differences produced large shifts in the fission density to the cylinder with the slightly higher reactivity. If the individual cylinders could be hand stacked safely as in Figure 2, the configuration of these systems before assembly to delayed critical was used. For systems that the individual cylinders could not be hand stacked safely, the configuration like that of Figure 3 was used.

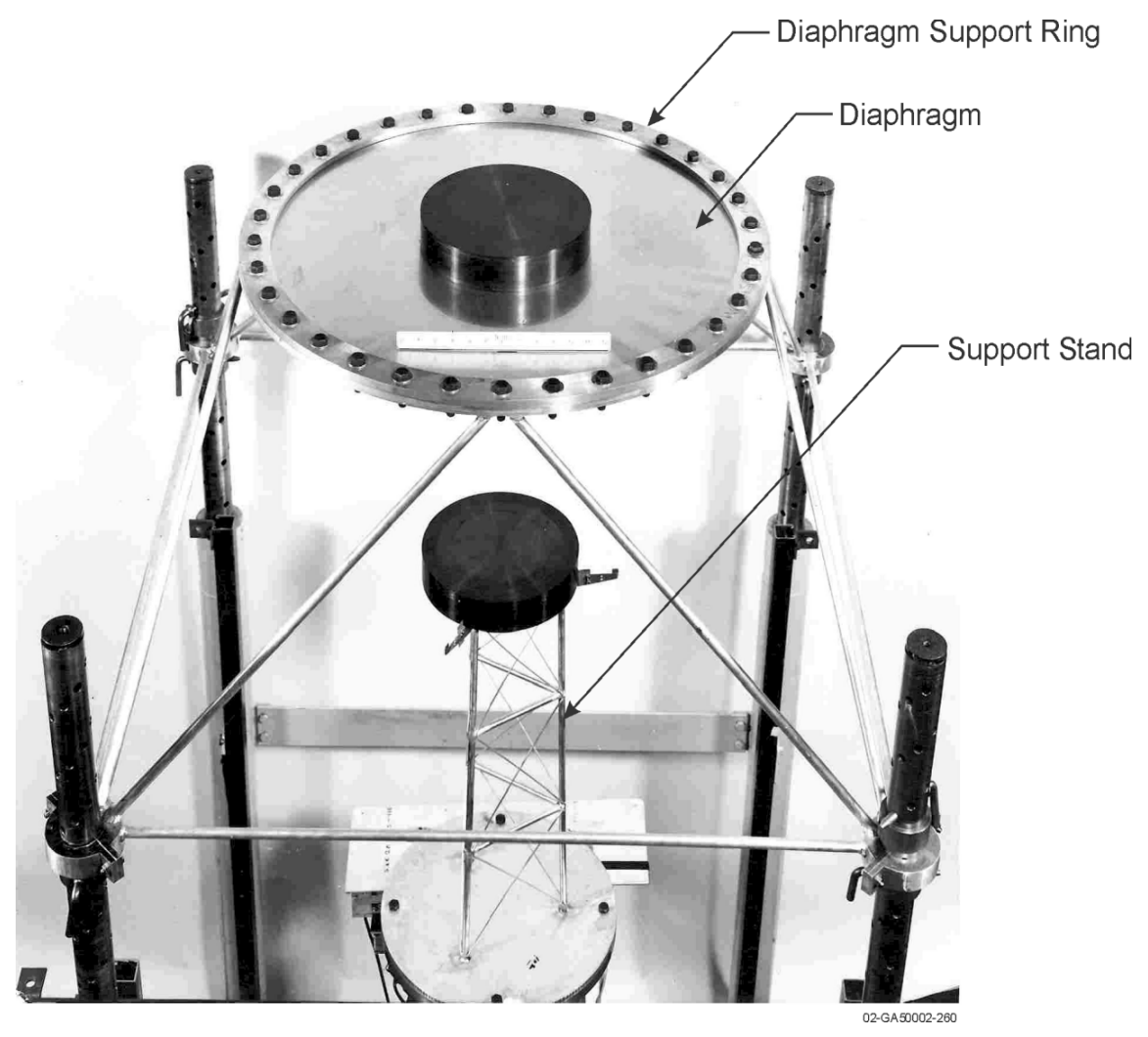

Figure 2. Configuration of the system before assembly for systems where the single cylinders could be hand stacked safely (this photo is of 11-in.-diameter cylinders, but this same type configuration was used for these 15-in.-diameter cylinders). 

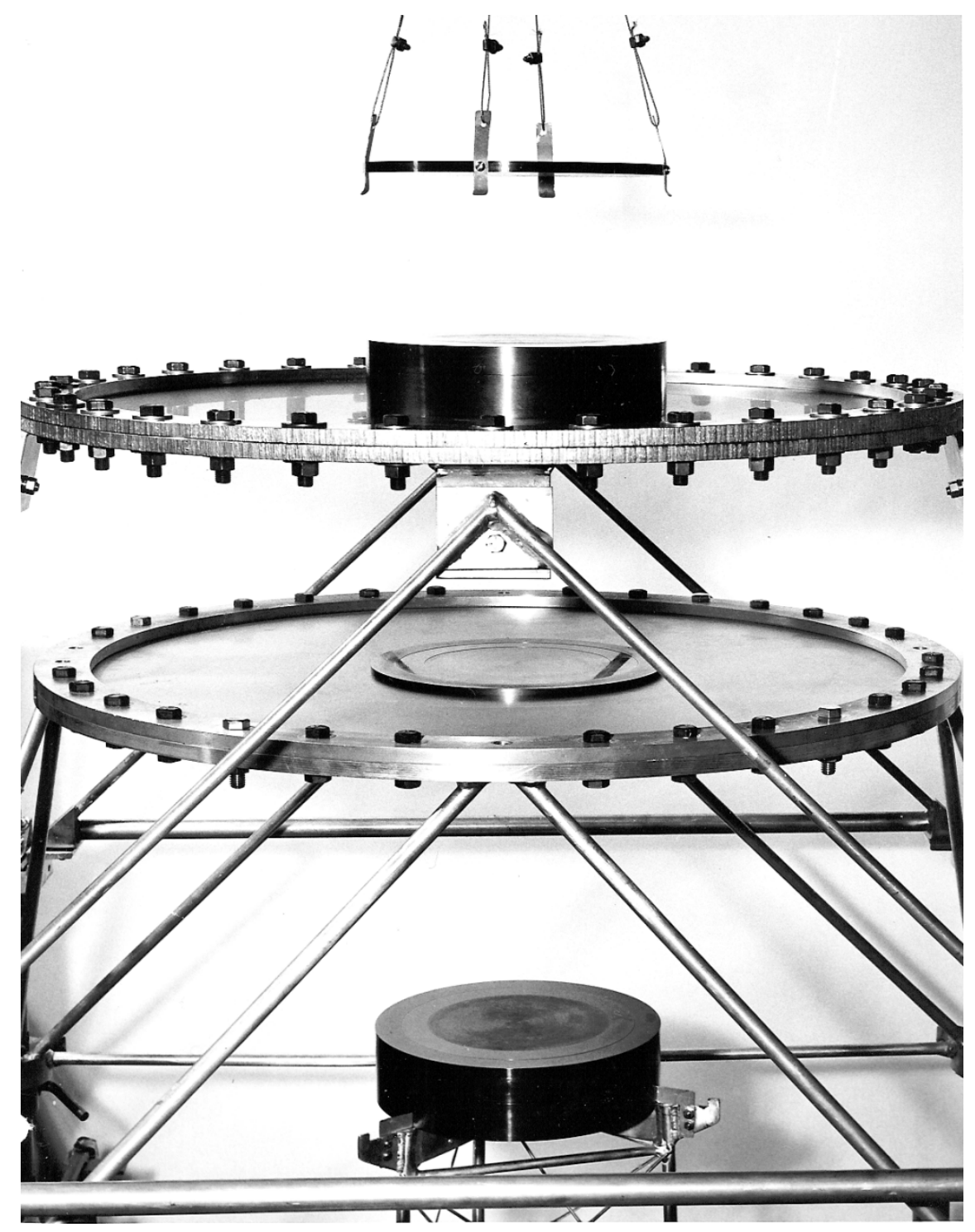

Figure 3. Configuration of the system before remote assembly for the higher reactivity single cylinders (this photo is of 11-in.-diameter cylinders, but this same type configuration was used for these 15-in.-diameter cylinders).

\subsection{Comments}

As the spacing between cylinders increases, the prompt neutron lifetime increases because the flight time of the neutrons between cylinders is a significant contribution to the neutron lifetime. Because the interaction depends on the travel time between cylinders, the effects of the neutron spectrum are significant and the agreement between calculations and measurements depends on the correct calculations of the neutron spectrum.

\subsection{Documentation}

The papers for this work have been presented at technical meetings and are as follows. 
J. T. Mihalczo, "Prompt neutron decay for loosely coupled delayed critical 38.1-cm.-diam uranium (93.2) metal cylinders," Transactions of the American Nuclear Society, V 75, Winter Meeting of the American Nuclear Society (ANS) and the European Nuclear Society (ENS) Washington, D.C. (December 1997). [OSTI \#426526]

J. T. Mihalczo, "Interacting Delayed Critical 38.1-cm-diam Uranium (93.2) Metal Cylinders at Large Distance," American Nuclear Society Annual Meeting, Reno, Nevada, Trans. Amer. Nucl. Soc., 74, 195 (1996).

\subsection{Suggested work}

The data and description of the materials and configuration are such that these measurements at delayed criticality could be a NEA and ICSBEP benchmarks. A draft on the experimental part of a report for the data benchmark for the data bases has been completed. In addition to completing the documentation of the experiments, a calculational modeling and uncertainty analysis, along with a comparison with experiment, needs to be performed. Because of the accuracy of Y-12 NSC in characterizing the materials and the accuracy of the experiments, it is expected that the uncertainties in the measured $k_{\text {eff }}$ will be below \pm 0.001 and as low as \pm 0.0002 .

\section{CRITICAL MEASUREMENTS WITH HEU METAL CYLINDERS AND ANNULI WITH THICK GRAPHITE REFLECTORS}

\subsection{Date of experiments and facility time}

These experiments were performed between July 16, 1964, and February 15, 1965, and used 45 operational days of ORCEF's critical facility time.

\subsection{Brief description of the measurements}

These measurements with enriched uranium metal in annular and cylindrical geometry were used to assess the criticality of graphite-reflected uranium metal. The solid cylinder diameters ranged from 7 to 15 in. in 2-in. steps. The annuli diameter varied from 15 to 9 in. with the inner diameters varying from $2 \mathrm{in}$. less than the outer diameter down to $7 \mathrm{in}$. less. As a result, the annuli had radial thicknesses from 1 to 4 inches. Some of the solid cylinders had thicknesses less than $1 \mathrm{inch}$. The reflector thicknesses varied from 3 to $20 \mathrm{in.}$ Eighty-two configurations were studied, and their critical masses ranged from $\sim 30$ to $\sim 100 \mathrm{~kg}$.

\subsection{Comments}

These extensive studies conducted for the Y-12 NSC determined the critical configurations of graphite-reflected, highly enriched uranium metal in annular and cylindrical geometry. The configurations with 1- and 2-in.-thick reflectors were benchmarked in HEU-MET-FAST-071. 


\subsection{Documentation}

J. T. Mihalczo, "Criticality of Graphite- and Polyethylene-Reflected Uranium (93.2) Metal Cylinders and Annuli," Nucl. Sci. Eng., 49, 489-504 (1972).

J. T. Mihalczo, "Randomly Pulse Neutron Measurements for Safeguards Interrogation, Graphite and Polyethylene Reflected Uranium-Metal Cylinders and Annuli," Y/DR-81, Union Carbide Corp. Nuclear Division, Oak Ridge Y-12 Plant (April 1972).

\subsection{Suggested work}

The data and description of the materials and configuration are such that these measurements at delayed criticality at ORCEF could be a NEA and ICSBEP benchmark. The experimental details should be documented. The systems have to be modeled and uncertainty analysis performed to determine the uncertainty in measured $\mathrm{k}_{\text {eff }}$ and the calculated $\mathrm{k}_{\mathrm{eff}}$ values compared with measured values. Because of the accuracy of Y-12 NSC in characterizing the materials and the accuracy of the experiments, it is expected that the uncertainties in the measured $\mathrm{k}_{\text {eff }}$ will be below \pm 0.001 and as low as \pm 0.0002 . Some of the uncertainty analysis would be similar to that for similar measurements with thin graphite reflectors (HEU-MET-FAST-071.

\section{CRITICAL EXPERIMENTS WITH 7-IN.-DIAMETER URANIUM METAL CYLINDERS WITH THIN STAINLESS-STEEL REFLECTOR ON TOP AND BOTTOM}

\subsection{Date of experiments and facility time}

These three experiments were performed from January 13-25 in 1965 and used 7 operational days at the ORCEF.

\subsection{Brief description of experiments}

These 7-in.-diameter uranium (93.15 wt. $\left.\%{ }^{235} \mathrm{U}\right)$ metal cylinders were assembled on the vertical assembly machine of the ORCEF and had stainless-steel reflectors $(1 / 2,1$, and 2 in. thick) only on the top and bottom. The configuration of the uranium cylinder with 1-in.-thick top and bottom reflector is given in Figure 4. These uranium metal had holes filled with tight fitting plugs. To achieve near delayed critical systems, a 1/32-in.-thick, $5 \times 5$-in.-square rectangular uranium metal part was used on top of the top 7-in.-diameter disc. Rossi- $\alpha$ measurement were also performed. 


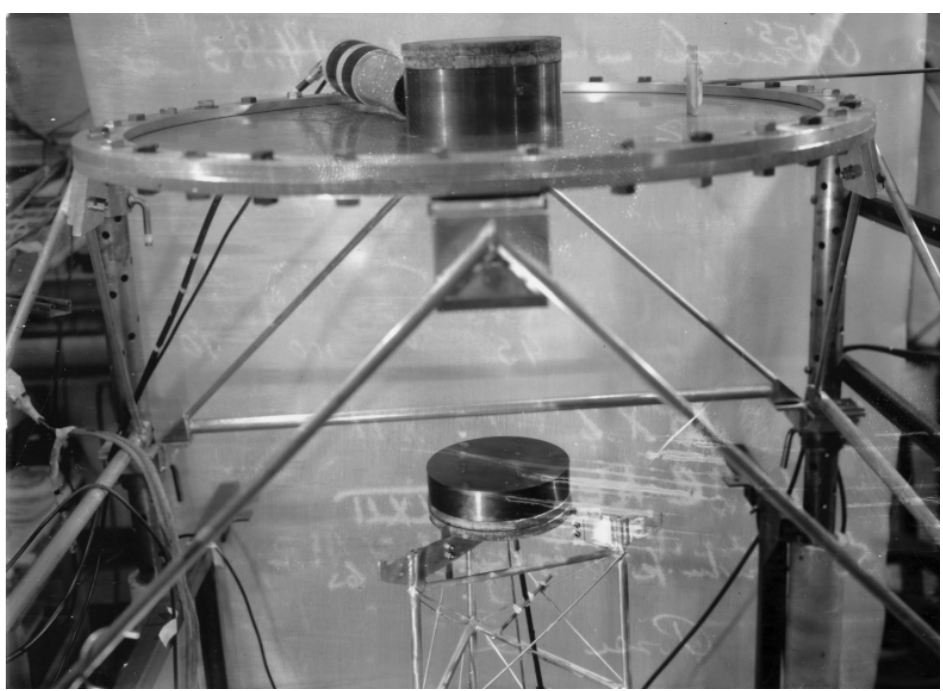

Figure 4. Configuration of 1-in.-thick bottom and top reflector on 7-in. diameter uranium metal cylinder on the vertical assembly machine at ORCEF (Rossi- $\alpha$ detector in place).

\subsection{Comments}

These measurements were performed to evaluate the stainless-steel cross section data for a near fission spectrum assembly.

\subsection{Documentation}

Some results of these experiments are given in the following reference.

J. T. Mihalczo, "Uranium (93.2) Metal Cylinders with Thin Stainless-Steel Reflectors," Nucl. Sci. Eng., 25, 444 (1966). [OSTI \#4520545]

\subsection{Suggested work}

The data and description of the materials and configuration are such that these measurements at delayed criticality at ORCEF could be a NEA and ICSBEP benchmark. Because of the accuracy of Y-12 NSC in characterizing the materials and the accuracy of the experiments, it is expected that the uncertainties in the measured $k_{\text {eff }}$ will be below \pm 0.001 and as low as \pm 0.0002 .

\section{CRITICAL MEASUREMENTS WITH THREE INTERACTION 15-IN.-DIAMETER HEU URANIUM METAL CYLINDERS}

\subsection{Date of experiments and facility time}

These eight experiments were performed in 1965 between August 27 and September 16 and September 24 to October 4 and used 7 operational days of ORCEF critical facility time. 


\subsection{Brief description of the measurements}

Eight assemblies of three interacting 15-in.-diameter coaxial symmetric uranium (93.14 wt. \% $\left.{ }^{235} \mathrm{U}\right)$ metal cylinders were assembled to delayed criticality without a moderator or reflector. The height of each cylinder of three interacting cylinder experiments varied from 1.25 to $2.00 \mathrm{in}$., with the spacing between individual cylinders adjusted to achieve delayed criticality. All interacting cylinders were assembled co-axially with their flat faces parallel, and their combined masses of each of the eight configurations varied between 182 and $325 \mathrm{~kg}$ of HEU metal. The spacing between the cylinders was the variable that was adjusted to achieve delayed criticality. The configuration of these measurements is given in Figure 5. The reactivity effects of the support structure were evaluated experimentally.

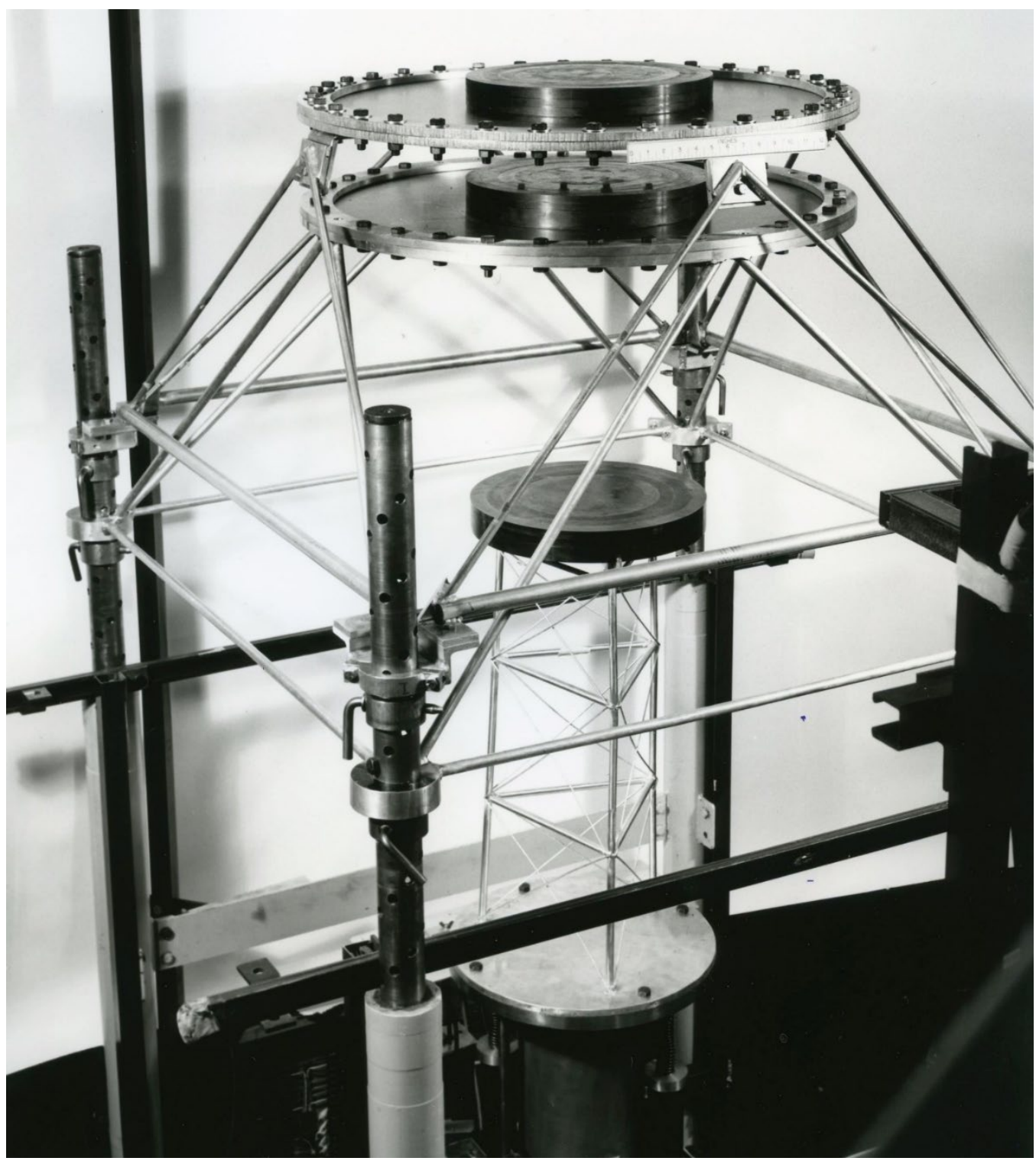

Figure 5. Three 15-in.-diameter HEU interacting uranium metal cylinders on the vertical assembly machine at ORCEF. 


\subsection{Comments}

As the spacing between cylinders increases, the prompt neutron lifetime increases because the flight time of the neutron between cylinders is significant compared with the neutron lifetime. Because the interaction depends on the travel time between cylinders, the effects of the neutron spectrum are significant and the agreement between calculations and measurements depends on the correct calculations of the neutron spectrum.

\subsection{Documentation}

J. T. Mihalczo, "Prompt Neutron Decay in Delayed Critical Assemblies of Three Interacting Cores," Trans. Am. Nucl. Soc. 10, 242 (1967). [OSTI \#4273797]

\subsection{Suggested work}

The data and description of the materials and configuration are such that these measurements at delayed criticality at ORCEF could be a NEA and ICSBEP benchmark. A draft on the experimental part of a report for the data benchmark for the data bases has been initiated. In addition to completing the documentation of the experimental work, the calculational modeling and uncertainty analysis, along with a comparison with experiment, needs to be performed. Because of the accuracy of Y-12 NSC in characterizing the materials and the accuracy of the experiments, it is expected that the uncertainties in the measured $\mathrm{k}_{\mathrm{eff}}$ will be below \pm 0.001 and as low as \pm 0.0002 .

\section{CRITICAL AND SUBCRITICAL MEASUREMENTS WITH JEMIMA PLATES AT ORCEF}

\subsection{Date of experiments and facility time}

These measurements were performed at ORCEF between July 14 and November 3, 1969, and used 60 days of ORCEF operational time.

\subsection{Brief description of the measurements}

These measurements utilized the JEMIMA (from LANL) 0.12-in.-thick HEU metal cylinders with various thicknesses of polyethylene $(1 / 16,1 / 8.1 / 4,3 / 8,1 / 2,1,1.5,2$, and 2-3/8 in.) between the plates. The measurements were performed on the vertical assembly machine of ORCEF. Partial pie-shaped pieces were available for adjustment to delayed criticality. Rossi- $\alpha$ and randomly pulsed neutron measurements with a time-tagged $\mathrm{Cf}$ source were performed at delayed criticality and at a variety of subcritical configurations. A typical configuration d source and detectors for the prompt neutron time decay measurement are given in Figure 6 for the material mounted on a stainless-steel diaphragm before completion of the critical assembly by raising the material on the vertical lift. The JEMIMA plates were numbered, and assemblies were constructed with the plates in numerical order from one at the bottom to the highest numbered 
plate at the top of the assembly. The plates were oriented with the surface with the number on top, and the part numbers of all plates were oriented in the same direction.

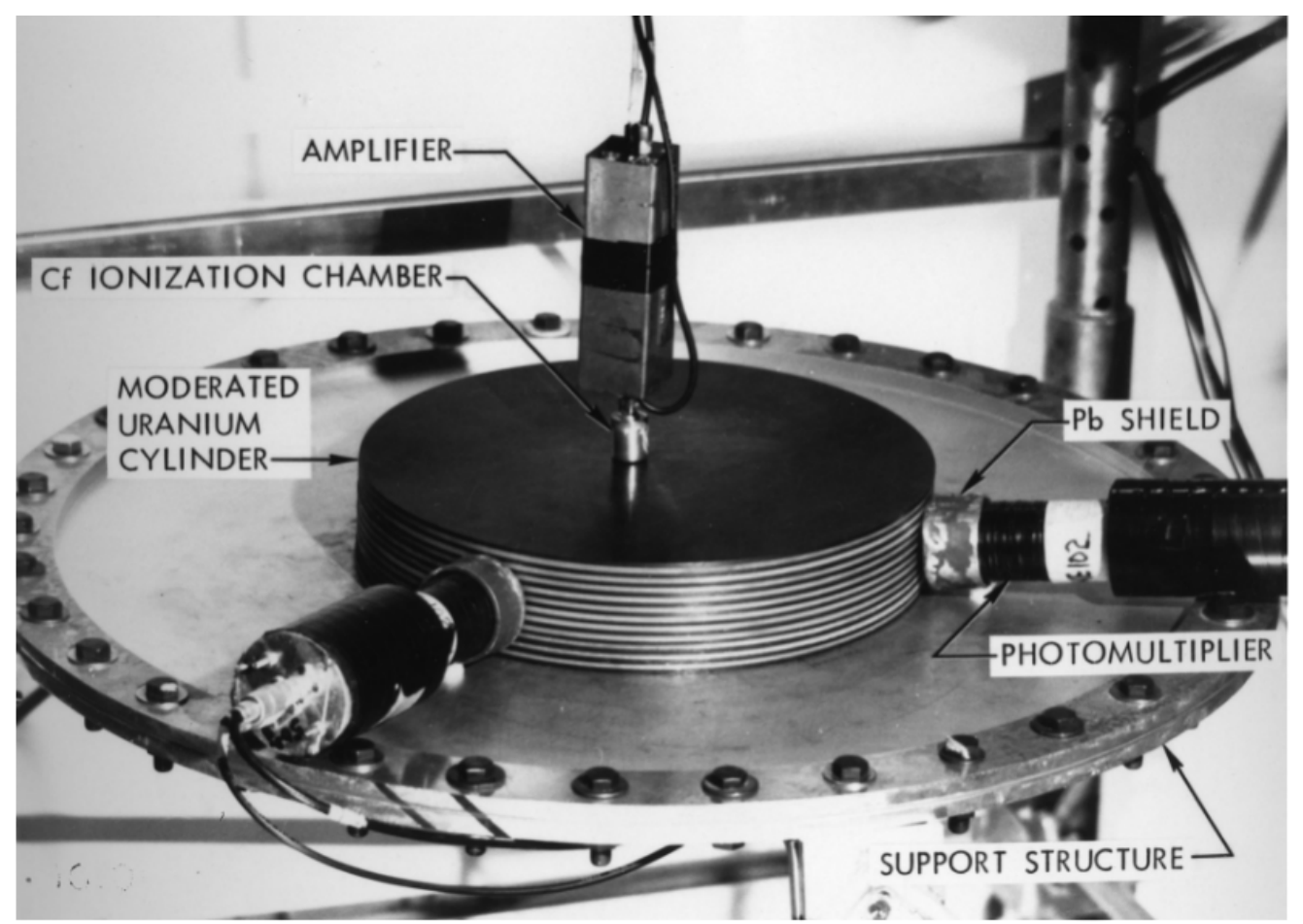

Figure 6. Typical configuration of source and detectors for prompt neutron decay measurements.

\subsection{Comments}

These measurements, taken at varying thicknesses of polyethylene, have neutron energy spectra ranging from a near fission spectrum to near thermal energies. Neutrons traveling between plates that have one scattering that reduces their energy to thermal will scatter to 90 degrees and have a reduced probability of reaching the adjacent plate. Forward scattered neutrons with a smaller change in energy tend to maintain their direction.

\subsection{Documentation}

The prompt neutron time decay data is recorded in ORNL logbook H00175, and the critical assembly data are recorded in ORNL logbook H0016?, or ORCEF logbook E-20 or INCESBEP Logbook 14 r.

J. T. Mihalczo, "Heterogeneous Critical Assemblies of Enriched Uranium Metal Plates and Polyethylene," American Nuclear Society 1995 Winter Meeting, San Francisco, California, Trans. Amer. Nucl. Soc., 73, 219-220 (1995). [OSTI \#411655] 


\subsection{Suggested work}

The data and description of the materials and configuration are such that these subcritical measurements could be a NEA and ICSBEP benchmark. Because of the accuracy of Y-12 NSC in characterizing the materials and the accuracy of the experiments, it is expected that the uncertainties in the measured $k_{\text {eff }}$ will be below \pm 0.001 and as low as \pm 0.0002 .

\section{CRITICAL AND SUBCRITICAL MEASUREMENTS FOR THE SHEBA CYLINDRICAL TANK OF URANYL FLUORIDE SOLUTION}

\subsection{Date of experiments and facility time}

These experiments were performed in 1980 between August 8 and September 15 and used $\mathbf{2 0}$ operational days of LANL's critical facility time.

\subsection{Brief description of the measurements}

These measurement with a 4.95 wt. $\%{ }^{235} \mathrm{U}$ enriched uranyl fluoride solution $\left(\mathrm{U}_{2} \mathrm{~F}_{2}\right.$ with a $\mathrm{H} / \mathrm{U}$ ratio of 20.43, uranium density of $1.04 \mathrm{~g} / \mathrm{ml}$, and solution density of $2.162 \mathrm{~g} / \mathrm{ml}$ ) were taken with a 54.6-cm-inside diameter, 6.35-mm-wall thickness, 105-cm-high unreflected stainless-steel tank filled to delayed criticality at a solution height of $36.5 \mathrm{~cm}$. Measurements were also performed at six subcritical heights down to $20 \mathrm{~cm}$. The $\mathrm{k}_{\text {eff }}$ varied from delayed criticality down to a $\mathrm{k}_{\text {eff }}$ of 0.82. Thirty-five measurements were performed by the $\mathrm{Cf}$ source-driven noise method with lithium glass scintillation detectors located outside the tank. The Cf source was located on the axis of the tank in a 6.02-cm-inside diameter central tube with a wall thickness of 0.065 in. at various heights but mostly at mid-height of the solution. Some inverse kinetics rod drop measurements of the higher reactivities were also performed.

\subsection{Comments}

These measurements are the only $\mathrm{Cf}$ source-driven noise analysis subcritical measurements for a low enriched aqueous solution.

\subsection{Documentation}

J. T. Mihalczo, E. D. Blakeman, W. T. King, and R. C. Kryter, "Cf-Source-Driven NeutronNoise Measurements of Subcriticality for a 4.95 wt. $\%{ }^{235} \mathrm{U}$-Enriched Uranyl Fluoride Solution Cylinder," Ann. Nucl. Energy, 13, 351-62 (1986).

J. T. Mihalczo, W. T. King, and J. A. Renier, "Calculated Ratios of Spectral Densities for Cf252-Driven Neutron Noise Subcriticality Measurements with a 5\%-U-235-Enriched Uranyl Fluoride Solution," Meeting of the American Nuclear Society, Los Angeles, Trans. Am. Nucl. Soc. 41 588-89 (1982). 


\subsection{Suggested work}

The data and descriptions of the materials and configuration are such that these $\mathrm{Cf}$ source-driven noise analysis measurements at critical and various subcritical configurations could be a NEA and ICSBEP benchmark.

\section{CRITICAL AND SUBCRITICAL MEASUREMENTS FOR A CYLINDRICAL TANK OF MIXED URANIUM-PLUTONIUM NITRATE SOLUTION}

\subsection{Date of experiments and facility time}

These experiments were performed in 1981 between July 13 and August 4 and used 18 operational days of Pacific Northwest National Laboratory's critical facility time.

\subsection{Brief description of the measurements}

These measurements were performed with a stainless-steel cylindrical tank (13.93-in. inside diameter with a wall thickness of 0.031 in.) of mixed uranyl $(127 \mathrm{~g} / \mathrm{L})$ and plutonium $(255 \mathrm{~g} / \mathrm{L})$ nitrate 5.4 molar solution. The initial measurements were at delayed critical, the solution height was reduced in steps to $4.0 \mathrm{in}$. The $\mathrm{Cf}$ source-driven noise analysis measurements were performed with the source located on the external surface of the tank, and after the initial measurements, a thin-walled tube was inserted on the axis of the tank so that the source could be centrally located in the tank. With an external source, the measurements were performed at the critical height of $20.9 \mathrm{in}$. and 10 measurements down to a solution height of $7.06 \mathrm{in}$. For the central source location, measurements were performed at the critical height of $23.89 \mathrm{in}$. and 10 down to a solution height of 4 in. Inverse kinetics measurements were performed at some selected heights for an alternate measurement of the subcriticality.

\subsection{Comments}

These measurements are unique in that a fissile solution contained both enriched uranium and plutonium.

\subsection{Documentation}

None

\subsection{Suggested work}

The data and description of the materials and configuration are such that these $\mathrm{Cf}$ source-driven noise analysis measurements at delayed critical and subcritical could be a NEA and ICSBEP benchmark. 


\section{BABCOCK AND WILCOX 1983 CRITICAL AND SUBCRITICAL EXPERIMENTS WITH PWR FUEL PINS}

\subsection{Date of experiments and facility time}

These experiments were performed in 1983 between August 1 and September 16 and used 35 operational days of critical facility time. In addition, preparation before and after the measurements took about 1 week to check, ship, and install equipment and then another week to remove the equipment and ship it back to ORNL.

\subsection{Brief description of the measurements}

The measurement with 2.459 wt. $\%{ }^{235} \mathrm{U}$ enriched uranium oxide fuel pins started at the delayed critical configuration of the fully assembled pressurized water reactor (PWR) core configuration with 1511 parts per million (ppm) boron in the water. This configuration is shown in Figure 7. After the initial measurements at delayed criticality in which the number of detectors and $\mathrm{Cf}$ source locations were varied, additional boron was added to the water moderator and reflector, with resulting boron concentrations of 1561, 1613, 1765, 1880, 2104, 2384, 2975, 3606, and 4303 ppm.

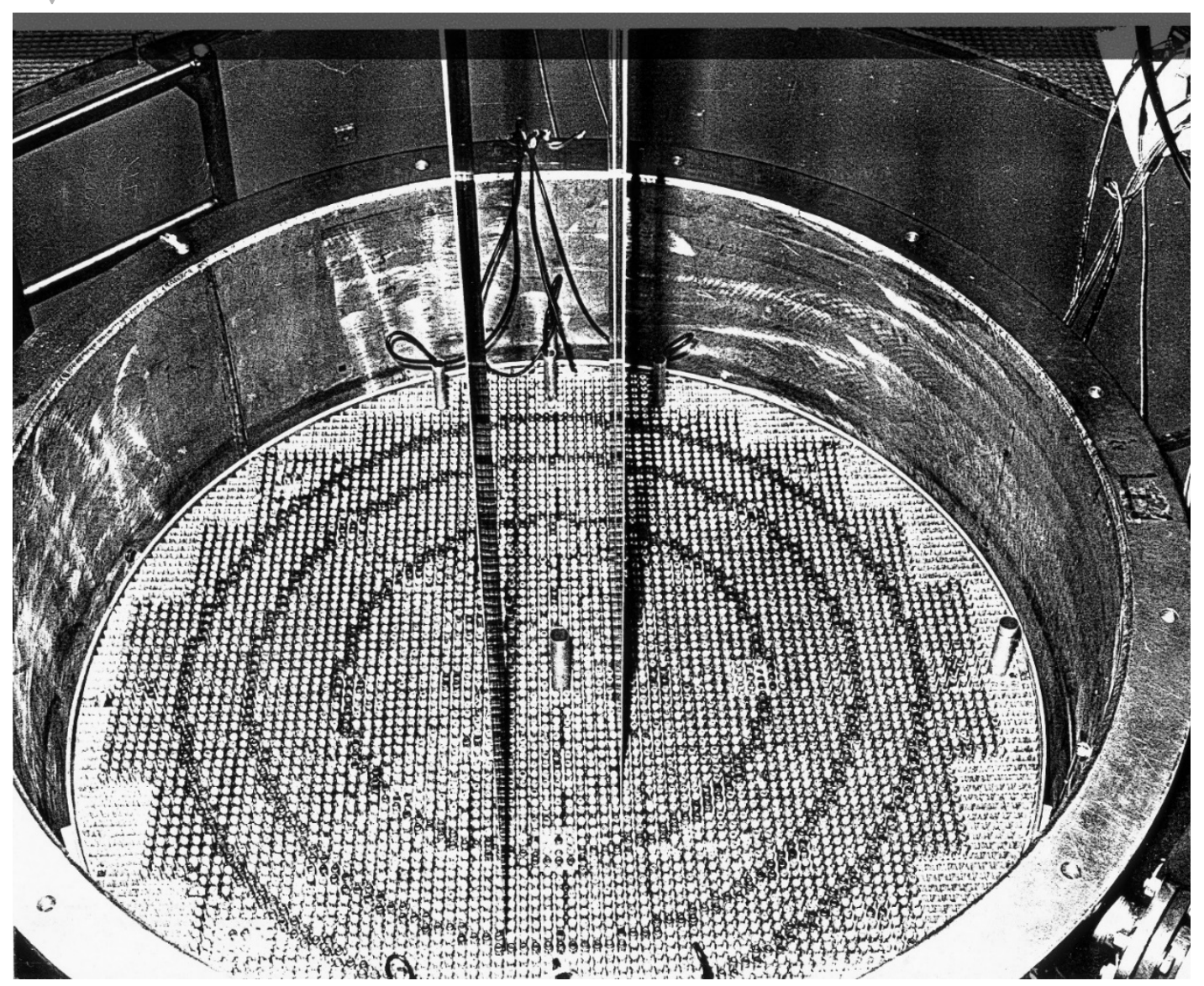

Figure 7. Configuration of the PWR fuel pins. 
The boron concentration was then changed to $2439 \mathrm{ppm}$ and then to $1510 \mathrm{ppm}$ (the latter being the concentration at delayed criticality). At each subcritical boron concentration, several subcritical measurements were performed in which the source and detector locations were varied. With the boron concentration for delayed criticality, the number of fuel pins was reduced sequentially in steps to cylindrical configurations of 3713, 2553,1281, 749, and 333 fuel pins.

The outlines of three of these cylindrical configurations are marked on the top of the full fuel pin loading shown in Figure 12.1. At each step, subcriticality measurements were performed for a variety of sources and detector locations. Finally, a $17 \times 17$ square array simulation of a single reactor fuel element was assembled, and additional measurements were performed. This configuration is depicted in Figure 8.

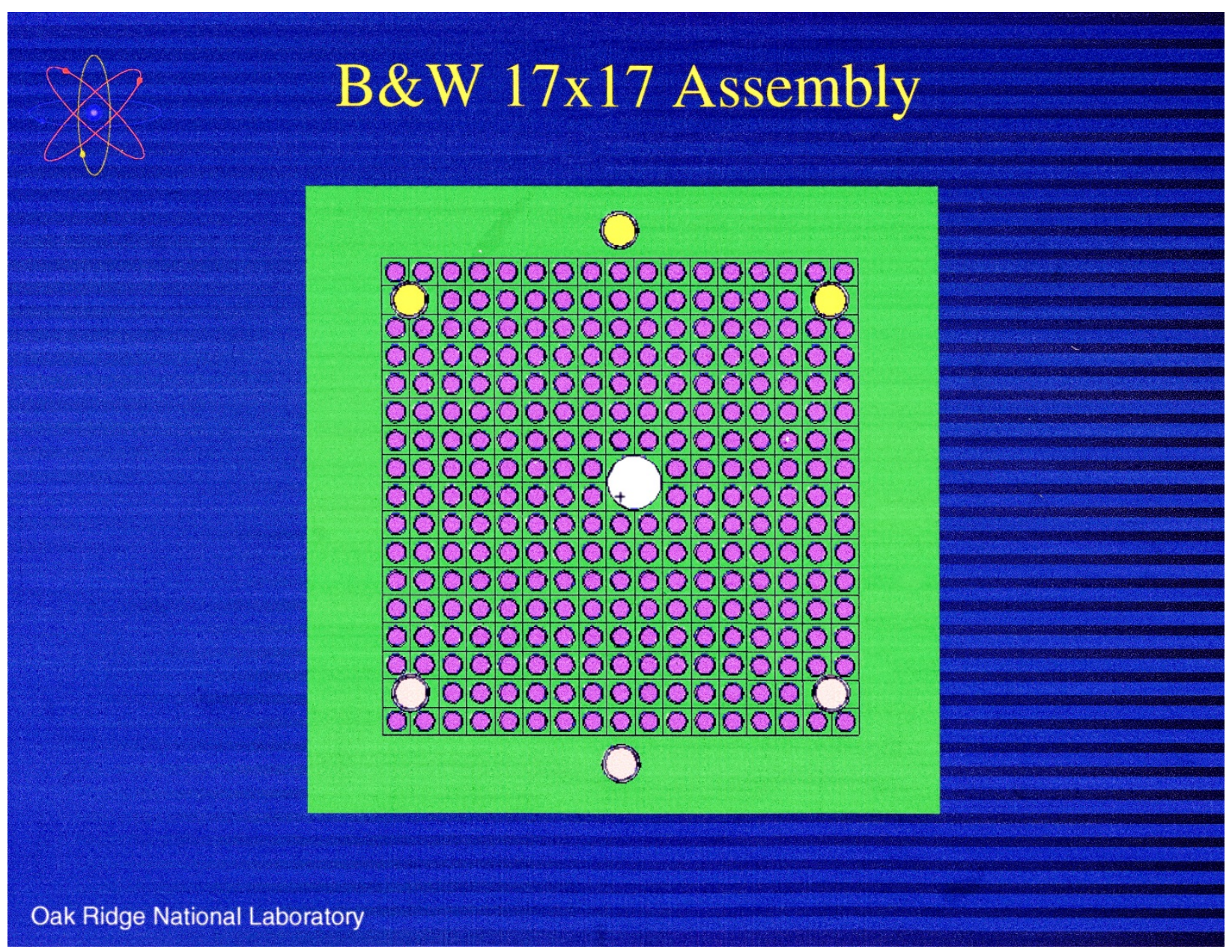

Figure 8. 17 × 17 PWR fuel assembly (white circles indicate locations of burnable poison rods).

\subsection{Comments}

Many calculations with PWR configurations were performed. However, the neutron spectrum in these experiments is much different from typical PWR configurations in that there are fewer lowenergy neutrons as boron is added to the water because of the absorption of neutrons by boron at 
low energy. The spectrum had higher energy components than usual because the boron concentration in the water for some measurements was tripled. In addition, as the number of fuel pins decreased, the leakage increased such that the effect of the reflector was increased and thus worth more in reactivity than the full fuel pin array. Most of the measurement used the $\mathrm{Cf}$ source-driven noise analysis measurements technique, which can be directly calculated by current Monte Carlo methods.

\subsection{Documentation}

Essentially none except for preliminary results given in another survey paper.

\subsection{Suggested work}

The data and description of the materials and configuration are such that these critical and subcritical experiments could be a NEA and ICSBEP benchmark.

\section{CRITICAL AND SUBCRITICAL MEASUREMENTS FOR A SLAB TANK OF PLUTONIUM NITRATE SOLUTION}

\subsection{Date of experiments and facility time}

These experiments were performed in 1985 and used $\mathbf{1 0}$ operational days of Pacific Northwest National Laboratory's critical facility time.

\subsection{Brief description of the measurements}

A series of experiments were performed in slab geometry using a mixed aqueous plutoniumuranium nitrate with 173 and $262 \mathrm{~g} / \mathrm{L}$ of plutonium and depleted uranium, respectively. Both the thickness of the slab for a fixed height of $\sim 71 \mathrm{~cm}$ and the height for a fixed thickness of $19.05 \mathrm{~cm}$ were varied. The base length of the slab was $106.7 \mathrm{~cm}$. The plutonium contained 91.1 wt. $\%{ }^{239} \mathrm{Pu}$, and the depleted uranium contained 0.57 wt. $\%{ }^{235} \mathrm{U}$. Cf source-driven noise

analysis measurements were performed at delayed criticality as the height was reduced in both configurations to a variety of subcritical configurations with keff values as low as 0.70 . Subcritical measurements were also performed by the inverse kinetics methods slightly below delayed criticality and break frequency noise analysis for $k_{\text {eff }}$ values as low as 0.70 , and the results were compared.

\subsection{Comments}

These experiments are the only subcriticality measurement with mixed plutonium-uranium aqueous solutions in slab geometry.

\subsection{Documentation}

J. T. Mihalczo, E. D. Blakeman, G. E. Ragan, R. C. Kryter, R. C. Robinson, H. Seino, T. Matsumoto, and H. Yamane, " ${ }^{252} \mathrm{Cf}$-Source-Driven Neutron Noise Measurements of Subcriticality for a Slab Tank Containing Aqueous Pu-U Nitrate," Proceedings of the 
International Seminar on Nuclear Criticality Safety, Tokyo, October 19-23, 1987. [OSTI \#6048203

J. T. Mihalczo, E. D. Blakeman, G. E. Ragan, R. C. Kryter, H. Seino, and R. C. Robinson, ${ }{ }^{252} \mathrm{Cf}-$ Source-Driven Noise Measurements of Subcriticality for a Slab Tank of Aqueous Pu-UNitrate," Nucl. Sci. Eng., 107, 35-57 (1991).

\subsection{Suggested work}

The data and description of the materials and configuration are such that this could be a NEA and ICSBEP benchmark.

\section{CRITICAL AND SUBCRITICAL MEASUREMENTS FOR AN ANNULAR TANK OF PLUTONIUM NITRATE SOLUTION}

\subsection{Date of experiments and facility time}

These experiments were performed in 1985 between March 16 and June 5 and used 10 operational days of Pacific Northwest National Laboratory's critical facility time.

\subsection{Brief description of the measurements}

A series of experiments were performed in annular tank geometry using a mixed aqueous plutonium-uranium nitrate with 173 and $262 \mathrm{~g} / \mathrm{L}$ of plutonium and depleted uranium, respectively. The height of the solution in the 53.34 -cm-outside diameter, 25.4-cm-inside diameter, $106.68-\mathrm{cm}$-high tank was varied from $73.8 \mathrm{~cm}$ at delayed criticality down to $23 \mathrm{~cm}$, and the $\mathrm{k}_{\text {eff }}$ value varied from delayed criticality down to 0.70 . The plutonium contained 91.1 wt. $\%{ }^{239} \mathrm{Pu}$, and the depleted uranium contained 0.57 wt. $\%{ }^{235} \mathrm{U}$. Californium sourcedriven noise analysis measurements were performed at delayed criticality and as the height was reduced. Subcritical measurements were also performed by the inverse kinetics methods slightly below delayed criticality and break frequency noise analysis for keff values as low as 0.70 , and the results were compared.

\subsection{Comments}

These experiments are the only subcriticality measurements with mixed plutonium-uranium aqueous solution in unreflected annular geometry.

\subsection{Documentation}

J. T. Mihalczo, E. D. Blakeman, G. E. Ragan, R. C. Kryter, H. Seino, and R. C. Robinson, “252 Cf-Source-Driven Neutron Noise Measurements of Subcriticality for an Annual Tank Containing Aqueous Pu-U Nitrate," Fall Meeting of the American Nuclear Society, Los Angeles, Trans. Am. Nucl. Soc. (1987).

J. T. Mihalczo, E. D. Blakeman, G. E. Ragan, R. C. Kryter, H. Seino, and R. C. Robinson, ${ }^{\prime 252}$ Cf-Source-Driven Neutron Noise Measurements of Subcriticality for an Annular Tank 
Containing Aqueous Pu-U Nitrate," Nucl. Technol., 94, 336-60 (1991). Also, ORNL/TM2014/461.

\subsection{Suggested work}

The data and descriptions of the materials and configuration are such that these $\mathrm{Cf}$ source-driven noise analysis measurements at delayed criticality and subcritical could be a NEA and ICSBEP benchmark.

\section{CRITICAL AND SUBCRITICAL MEASUREMENT WITH A MOCKUP OF THE SPACE POWER REACTOR-SP-100}

\subsection{Date of experiments and facility time}

These experiments were performed in December 1988 and used 10 operational days of Zero Power Physics Reactor (ZPPR) critical facility time at Argonne National Laboratory, Idaho.

\subsection{Brief description of the measurements}

These experiments investigate the ability of the Cf source-driven noise analysis to monitor the loading and startup of this reactor. The measurements were performed in reverse order starting at delayed critical and then examined subcritical configurations. This reactor mock-up consisted of a HEU core with a beryllium reflector. Sixty californium source-driven noise analysis measurements were performed for a variety of configurations to evaluate the ability of this method to monitor the initial loading and determine the reactivity of a variety of control rod configurations.

\subsection{Comments}

These measurements are unique in that they were used to evaluate the applicability of the $\mathrm{Cf}$ source-driven noise analysis subcriticality measurement method for the initial approach to critical of a reactor.

\subsection{Documentation}

None for these measurements, although there are NEA benchmarks for similar experiments.

\subsection{Suggested work}

The data and description of the materials and configuration are such that these $\mathrm{Cf}$ source-driven noise analysis measurements at delayed criticality and subcritical could be a NEA and ICSBEP benchmark. Four benchmarks already exist for this reactor mock-up at delayed criticality. 


\section{SUBCRITICAL MEASUREMENT WITH HEU URANYL NITRATE CYLINDRICAL SOLUTION TANK WITH VARYING SOLUTION CONCENTRATIONS}

\subsection{Date of experiments and facility time}

These experiments were performed in 1983 between May 6 and November 12 and used 70 operational days of ORCEF critical facility time.

\subsection{Brief description of the measurements}

The solution concentration of uranium $\left(93.16 \mathrm{wt} . \%{ }^{235} \mathrm{U}\right)$ in the uranyl nitrate solution was varied in 15 steps from $13.7 \mathrm{~g}{ }^{235} \mathrm{U} / \mathrm{L}$ to $0.3 \mathrm{~g} / \mathrm{L}$ and then 0.0 (water). To minimize the handling hazard, the solution had no free acid content. The inside diameter of the tank was in. and was filled to a height of $14.5 \mathrm{in}$. The neutron multiplication factor, $\mathrm{k}_{\mathrm{eff}}$, varied from 0.9 to 0 . Californium source-driven noise-analysis measurements $(\sim 160)$ were taken at each solution concentration with a variety of detectors, detector locations, and source locations. In the solution, two ${ }^{3} \mathrm{He}$ proportional counters in aluminum tubes were used and external to the tank, plastic and liquid scintillators.

\subsection{Comments}

These experiments are unique in that the uranyl nitrate solution concentration was reduced to zero and resulted in $\mathrm{Cf}$ source-driven noise analysis measurements at all concentrations down to pure water.

\subsection{Documentation}

J. T. Mihalczo, W. T. King, E. B. Johnson, and E. D. Blakeman, "Subcriticality Measurements for a Fuel Solution Tank with Changing Fuel Concentration using the CF-252-SourceDrivenNoise Analysis," Meeting of the American Nuclear Society, San Francisco, Trans. Am. Nucl. Soc. 45, 337-38 (1983).

\subsection{Suggested work}

The data and description of the materials and configuration are such that these $\mathrm{Cf}$ source-driven noise analysis subcritical measurements could be a NEA and ICSBEP benchmark.

\section{SUBCRITICAL INTERACTING HEU URANIUM METAL SEPARATED BY VARIOUS THICKNESSES OF BOROPLASTER}

\subsection{Date of experiments and facility time}

These subcritical Cf source-driven noise analysis measurements experiments were performed at ORCEF between September 9 and December 6, 1984, and used 32 days of facility time. 


\subsection{Brief description of the measurements}

Californium source-driven noise analysis subcriticality measurements were performed for interaction experiments with various thicknesses ( 0.38 to 5.7 in.) of boroplaster (each boroplaster was $\sim 0.38$ in. thick with a diameter of 7 in.) between 7 -in.-diameter HEU metal cylinders.

\subsection{Comments}

None

\subsection{Documentation}

None

\subsection{Suggested work}

The data and description of the materials and configuration are such that these subcritical measurements could be a NEA and ICSBEP benchmark.

\section{SUBCRITICAL MEASUREMENT WITH TWO INTERACTING URANYL NITRATE SOLUTION TANKS}

\subsection{Date of experiments and facility time}

These subcritical experiments of interest to nuclear criticality safety at the Y-12 NSC were performed in 1985 and used $\mathbf{5 5}$ days of ORCEF critical facility time.

\subsection{Brief description of the measurements}

Californium source-driven noise analysis measurements were performed for subcritical configurations of two cylindrical tanks with their axes parallel. The tanks were filled with $480 \mathrm{~g} / \mathrm{L}$ aqueous solution of highly enriched uranyl nitrate to a height of $90 \mathrm{~cm}$. The separation between the tanks was varied from contact to $40 \mathrm{in}$. After initial measurement, the solution in one tank was diluted to $140 \mathrm{~g} / \mathrm{L}$ and measurements were taken. Then the concentration of the solution in both tanks was $140 \mathrm{~g} / \mathrm{L}$, and measurements were taken and subsequently continued. At one stage, measurements were taken with one tank full to $90 \mathrm{~cm}$ and the other tank half full. Measurements were taken as the tanks were initially filled as a function of height (Figure 9). 


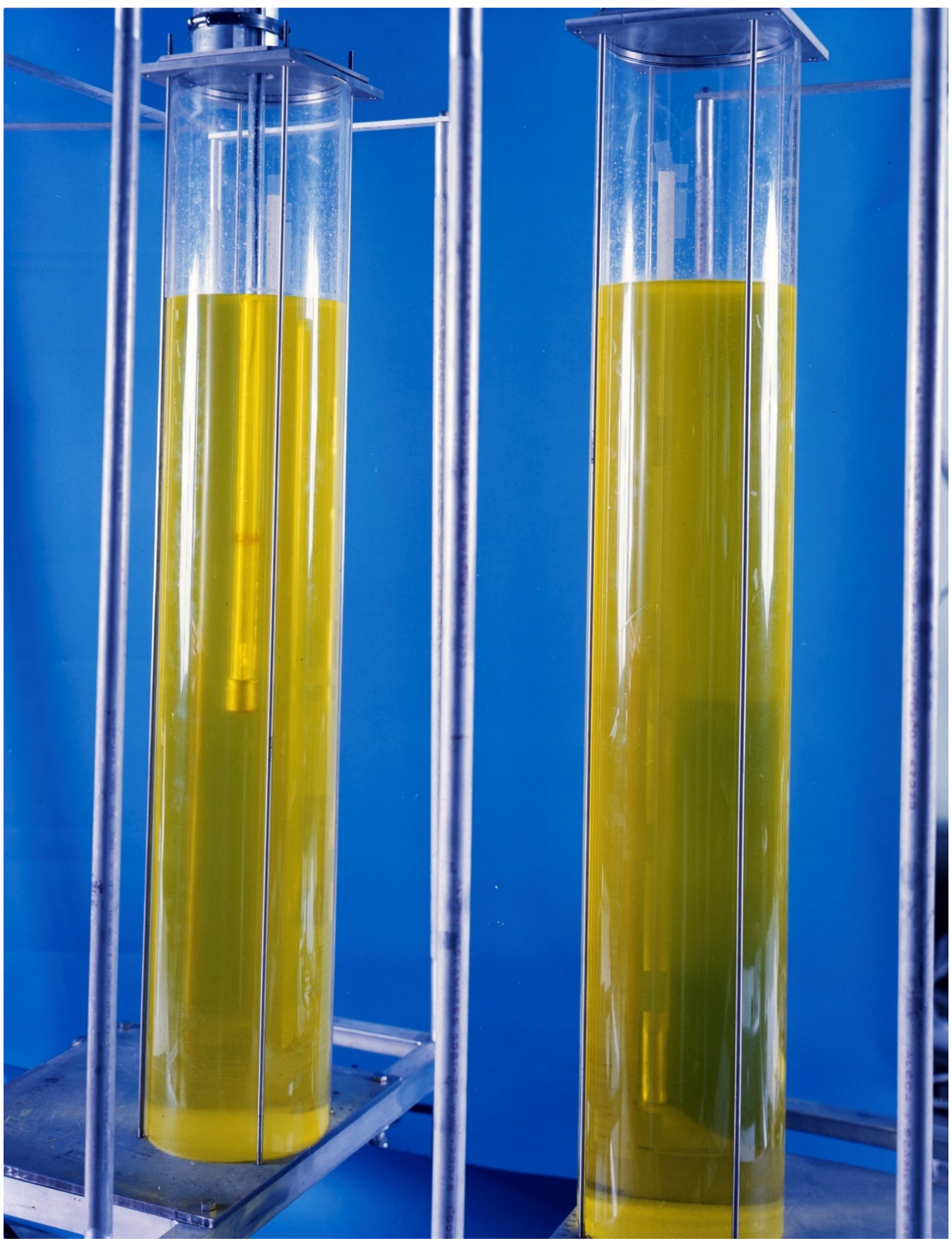

Figure 9. Interacting solution tanks with the same fissile concentration with the Cf source in the center of the left tank. 


\subsection{Comments}

Careful measurements taken using the Cf source-driven noise analysis subcriticality measurement method with interacting tanks of aqueous uranyl nitrate solution could provide the bases of NEA and INCSBEP benchmarks. They are unique in that the neutron multiplication factor depends on the neutrons traveling between tanks. The interaction between tanks determines the correlation between source events on one tank and detectors on the other tank.

\subsection{Documentation}

J. T. Mihalczo, E. D. Blakeman, and W. T. King, "Subcriticality Measurements for Two Coupled Uranyl Nitrate Solution Tanks Using ${ }^{252}$ Cf-Source-Driven Neutron Noise Analysis Methods," Meeting of the American Nuclear Society, Reno, Nevada, Trans. Am. Nucl. Soc. 52, 640-42 (1986).

\subsection{Suggested work}

The data and description of the materials and configurations are such that these $\mathrm{Cf}$ source-driven noise analysis subcritical measurements could be a NEA and ICSBEP benchmark.

\section{SUBCRITICAL MEASUREMENT WITH HEU URANYL NITRATE SAFE STORAGE BOTTLES}

\subsection{Date of experiments and facility time}

These experiments of interest to nuclear criticality safety at the Y-12 NSC were performed between Dec 21, 1985, and March 18, 1986, and used 42 operational days of ORCEF critical facility time.

\subsection{Brief description of the measurements}

These subcritical measurements with up to six 5-in.-diam. "safe" storage bottles of aqueous uranyl nitrate solution located in close contact and separated used the Cf source-driven noise analysis method. Measurement were performed at a variety of source locations and with ${ }^{3} \mathrm{He}$ proportional counters at a variety of locations and adjacent to the bottles. The solution concentration was in grams per liter with no free acid content; the enrichment was the density in grams per cc. The configurations were a linear array of one to three bottles, a triangular array of three bottles, square arrays of four and six bottles. The spacing between the bottles was varied.

\subsection{Comments}

These measurements are the only subcritical measurements with interacting safe storage bottles. Safe storage bottles are such that a single bottle is nuclear criticality safe with any concentration of uranium in aqueous solution. 


\subsection{Documentation}

J. T. Mihalczo, E. D. Blakeman, and G. E. Ragan, “ ${ }^{252}$ Cf-Source-Driven Neutron Noise Measurements for Three Interacting Tanks of Uranyl Nitrate Solution," Meeting of the American Nuclear Society, Dallas, June 7-11, 1987, Trans. Am. Nucl. Soc. 54, 208-9 (1987).

J. T. Mihalczo, E. D. Blakeman, and G. E. Ragan, "Subcritical Interaction Experiments with Four Safe Storage Bottles Containing Aqueous Uranyl Nitrate," Proceedings of the International Seminar on Nuclear Criticality Safety, Tokyo, October 19-23, 1987.

J. T. Mihalczo, E. D. Blakeman, and G. E. Ragan, “252Cf-Source-Driven Noise Analysis Measurements for Six Interacting Safe Bottles of Aqueous Uranyl Nitrate," Trans. Am. Nucl. Sci. 57, 133-34 (1988). [OSTI \#5523047]

J. T. Mihalczo, E. D. Blakeman, and G. E. Ragan, "Subcritical Interaction Experiments with Four and Six Storage Bottles of Uranyl Nitrate Solution," Proceedings of the International Seminar on Nuclear Criticality Safety, Tokyo, October 19-23, 1987.

\subsection{Suggested work}

The data and descriptions of the materials and configuration are such that these $\mathrm{Cf}$ source-driven noise analysis subcritical measurements could be a NEA and ICSBEP benchmark.

\section{SUBCRITICAL MEASUREMENT WITH HIGHLY ENRICHED URANIUM HYDRIDE CYLINDERS}

\subsection{Date of experiments and facility time}

These experiments were performed in July 1989 and used $\mathbf{5}$ operational days of LANL's critical facility time.

\subsection{Brief description of the measurements}

Californium source-driven noise analysis subcritical measurements were performed July 6 and 7 in 1989 by ORNL at the LANL Critical Experiments Facility for unreflected 15.0-cm-diameter uranium ( $\sim 91$ wt. $\%{ }^{235} \mathrm{U}$ enriched) hydride (H/U ratio of three) cylinders of various heights. The $\mathrm{UH}_{3}$ powder was in stainless steel cans with a density of the hydride of $\sim 10 \mathrm{~g} / \mathrm{cm}^{3}$ and was contained in thin cylindrical stainless-steel cans. The enrichment of the uranium metal to make the hydride was $93.15 \mathrm{wt} . \%{ }^{235} \mathrm{U}$. Four 3.00-cm-high (identified as I, II, III, and IV) and two 2.0-cm-high (identified as A and B) hydride canned cylinders were available. The 0.5 -cm-thick steel table on which the configurations were assembled was located 3 meters from the nearest two walls. Thick hydride cylinders were stacked on a $0.5-\mathrm{cm}$.-thick table $86 \mathrm{~cm}$ above the concrete floor. Configurations of cylinders 11,14 , and $16 \mathrm{~cm}$ high were assembled with nominal heights of 12,14, and $16 \mathrm{~cm}$ and masses of 22,676, 26,264, and 29,858 $\mathrm{g}$ (including the steel cans), respectively. 


\subsection{Comments}

These measurements are the only unreflected configurations of uranium hydride. The neutron spectrum is a slightly slowed-down fission spectrum. Uranium hydride with various reflectors were benchmarked in HEU-COMP-INTER-003.

\subsection{Documentation}

J. T. Mihalczo, V. K. Paré, and E. D. Blakeman, “The ${ }^{252}$ Cf-Source-Driven Noise Measurements of Unreflected Uranium Hydride Cylinders,” Trans. Am. Nucl. Soc. 63, 221 (1991).

\subsection{Suggested work}

The data and description of the materials and configuration are such that these $\mathrm{Cf}$ source-driven noise analysis subcritical measurements could be a NEA and ICSBEP benchmark. The starting point for the documentation of the material uncertainties and analysis should parallel that in HEU-COMP-INTER-003.

\section{SUBCRITICAL MEASUREMENTS WITH TWO HIGHLY ENRICHED URANIUM METAL CYLINDERS WITH VARIOUS MATERIALS BETWEEN THEM}

\subsection{Date of experiments and facility time}

These unattended classified subcritical experiments for the nuclear criticality safety of Y-12 NSC were performed intermittently from 1990 to 1992 and used 225 operational days in a material balance area of the Y-12 NSC.

\subsection{Brief description of the measurements}

Materials of various thicknesses that were of interest to nuclear criticality safety were placed between two coaxial canned HEU metal cylinders 6 in. in diameter, and a variety of measurements were taken using the $\mathrm{Cf}$ source-driven noise analysis method. A configuration of the $\mathrm{Cf}$ source and detectors for measurements with a single canned cylinder is shown in Figure 10. 


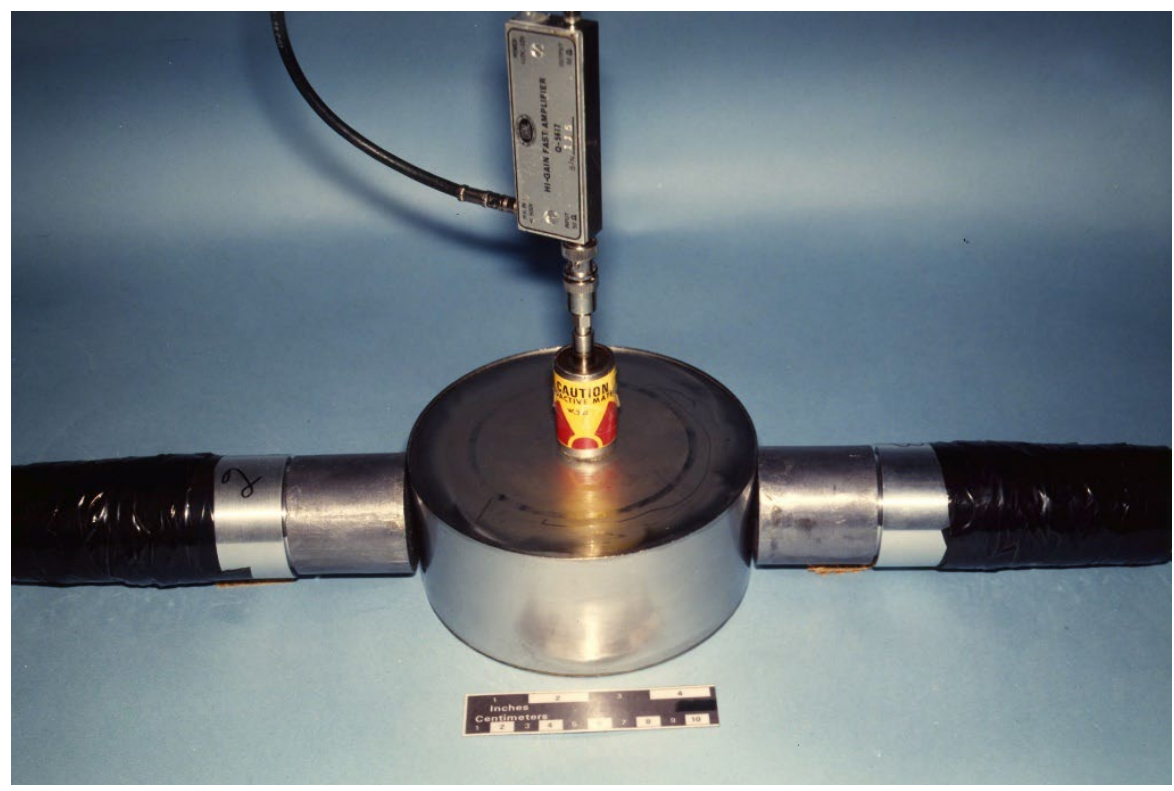

Figure 10. One of six canned 6-in.-diameter HEU metal castings.

\subsection{Comments}

The interactions of fission neutrons through various materials of interest to nuclear criticality safety were studied using these measurements. The materials from Y-12 NSC and the configurations are accurately described and would provide very accurate benchmark data for the Y-12 NSC.

\subsection{Documentation}

None

\subsection{Suggested work}

The data and description of the materials and configuration are such that these source-driven noise analysis subcritical measurements could be described in an Oak Ridge classified report on the quality of a NEA or ICSBEP benchmark.

\section{SUBCRITICAL MEASUREMENTS WITH A HEU CASTING IN A CONCRETE STORAGE VAULT}

\subsection{Date of experiments and facility time}

These measurements of interest to nuclear criticality safety at Y-12 were performed intermittently between September 1993 and May 1994 and used 32 days of measurement setup in a storage vault in a material balance area at the Y-12 NSC. Measurement were performed unattended over nights and weekends. 


\subsection{Brief description of the measurements}

Californium source-driven frequency analysis measurements for a HEU ( 93.2) metal storage vault at the Oak Ridge Y-12 NSC were taken to provide data for verification of calculational methods for criticality safety and to assess the effects of any loss of unbound water from the concrete (Figure 11). The measurements showed that 3 by 3 by 10 arrays of $\sim 18$-kg uranium annular castings are essentially infinite because the results for the 5 by 5 by 10 arrays are not statistically different from those of the smaller arrays. These measured frequency analysis parameters are presented, and inferred subcritical neutron multiplication factors from the measurement are compared with the calculations.

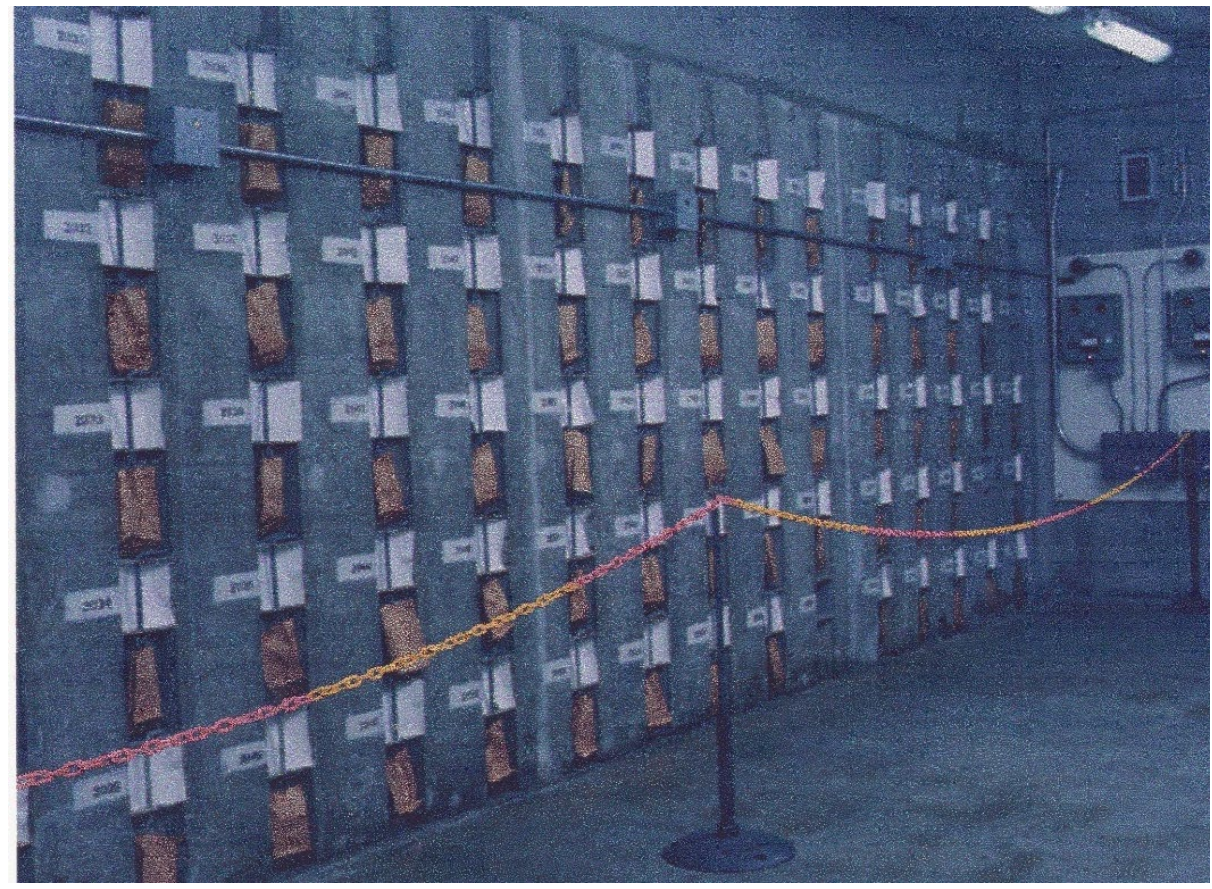

Figure 11. Concrete Storage Vault at Y-12 NSC.

\subsection{Comments}

These subcritical measurements were performed in Vault-16 (previously monitored by the IAEA) for nuclear criticality safety at the Y-12 NSC to assess the adequacy of the concrete of the vault to isolate uranium metal castings. Over time the hydrogen content of the concrete changes.

\subsection{Documentation}

In addition to the logbook and the data files from the $\mathrm{Cf}$ source-driven noise analysis measurements, this work has been reported in the following references.

J. T. Mihalczo, T. E. Valentine, and L. D. Phillips, "Subcritical Measurements for a HEU Storage Vault at the Y-12 Plant Using the ${ }^{252}$ Cf-Source-Driven Frequency Analysis Method," Nuclear Safety, vol. 38, Issue 1, 10-24 January-March 1997 (1997). 
J. T. Mihalczo, T. E. Valentine, and L. D. Phillips, "Subcritical Measurements for a HEU Storage Vault at the Y-12 Plant Using the ${ }^{252} \mathrm{Cf}$-Source-Driven Frequency Analysis Method," Y/DD-730 R1, Oak Ridge Y-12 Plant (June 1997).

J. T. Mihalczo, T. E. Valentine, and L. D. Phillips, "Subcritical Measurements for Calculational Verification of HEU Tube Vault Storage at the Y-12 Plant," Y/DD-661, Oak Ridge Y-12 Plant, (September 1995). [OSTI \#162496]

\subsection{Suggested work}

The data and descriptions of the materials and configuration are such that these subcritical measurements could be a NEA and ICSBEP benchmark.

\section{SUBCRITICAL MEASUREMENT WITH UP TO FIVE ADJACENT UNREFLECTED HEU CASTINGS}

\subsection{Date of measurements and facility time}

These measurements were taken in August 2006 in a material balance area of the Y-12 NSC and were of interest to nuclear criticality safety and took $\mathbf{1 3}$ days.

\subsection{Brief description of the measurements}

These measurements for Y-12 NSC nuclear criticality safety involved up to $90 \mathrm{~kg}$ of uranium (93.2 wt. $\%{ }^{235} \mathrm{U}$ ) metal castings. Each of the annular castings had an outside diameter of $5 \mathrm{in}$., an inside diameter of $3.5 \mathrm{in}$., a height of $6 \mathrm{in}$., weighed about $18 \mathrm{~kg}$, and was contained in stainless steel cans for contamination control. Active interrogation measurement with 1, 2, 3, 4, and 5 adjacent castings $(>2)$ were performed both with a time-tagged CF source and a DT neutron generator. The measurements were performed with four $1 \times 1 \times 6$-in.-long plastic scintillators adjacent to the casting in a variety of locations, with the long dimensions parallel to the axis of the casting. A typical configuration is given in Figure 12. 


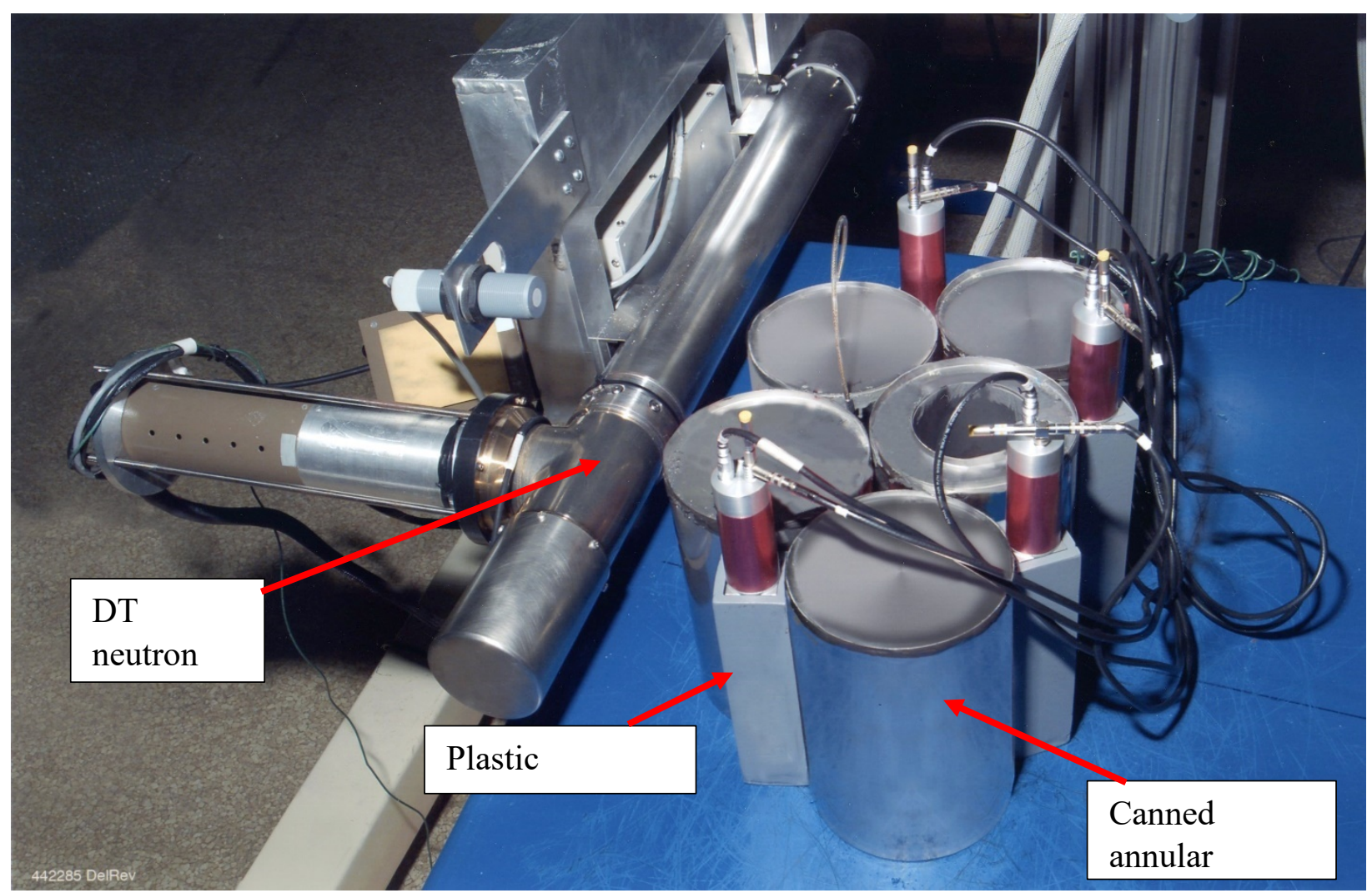

Figure 12. A five-casting configuration with a DT neutron generator.

\subsection{Comments}

These are the only measurements where time-tagged $\mathrm{Cf}$ source-driven and DT neutron generator time and directionally tagged neutron time decay measurements have both been performed. The accelerator-driven measurements could be used to assess a proposed subcriticality monitoring method for accelerator-driven fission multiplying systems by comparing the results of the accelerator-driven measurements with those from the $\mathrm{C}$ f source-driven analysis.

\subsection{Documentation}

John T. Mihalczo, James J. Henkel, Michael C. Wright, Daniel E. Archer, James A. Mullens, Subcriticality Measurements with HEU (93.2) Metal Annular Storage Castings, Oak Ridge National Laboratory, ORNL/TM-2007/134 (2007). [OSTI \#988200]

\subsection{Suggested Work}

The data and description of the materials and configuration are such that these subcritical measurements could be a NEA and ICSBEP benchmark. 


\section{CONCLUSIONS}

This report documents a wide variety of critical and subcritical measurements that could be Nuclear Energy Agency (NEA) or International Criticality Safety Benchmark Program (ICSBEP) benchmarks. The experiments were divided into four classes: critical experiments only, critical and subsequent subcritical experiments, subcritical experiments (all performed in critical experiment facilities), and subcritical measurements performed in material balance areas at the Y-12 National Security Complex (NSC) for Y-12 nuclear criticality safety. Measurements at critical and subsequently subcritical were taken in critical facilities at Oak Ridge National Laboratory, Los Alamos National Laboratory, Pacific Northwest National Laboratory, and Babcock and Wilcox at Lynchburg, Virginia, and used $\sim 350$ operational days of critical facility time. (Some measurements were omitted.) Measurements only at subcritical at the Oak Ridge Critical Experiments Facility (ORCEF) used $\sim 200$ operational days, and subcritical measurements in material balance areas of the Y-12 NSC used 350 operational days, many of which were unattended measurements. Because of the high cost of critical facility time and that only one facility is currently available for measurements in the United States, it is very costeffective to mine the existing data to produce benchmarks, such as those already in NEA and ICSBEP data bases. Repeating these measurement, if allowed, would cost many tens of millions of dollars. For measurements at ORCEF, the material descriptions from Y-12 NSC and the accuracy of the configurations (bases on experience with existing NEA or ICSBEP of ORCEF measurement benchmarks) should result in uncertainties in measured $\mathrm{k}_{\text {eff }}$ values lower than \pm 0.001 and may be as low as \pm 0.0002 , thus allowing more accurate comparisons between measurements and calculations and verification of calculations. 


\section{APPENDIX A. NEA AND ISBEP BENCHMARKS}

The following experiments at the Oak Ridge Critical Facility have been included in the Nuclear Energy Agency International Handbook of Evaluated Criticality Safety Benchmark Experiments.

Identifier and Title in the data base

HEU-MET-FAST-007 Uranium Metal Slabs Moderated with polyethylene, Plexiglas and Teflon

HEU-MET-FAST-051 Uranium (93.2) Metal Cylinders (7-inch, 9- inch, 11-inch, 13-inch,15Inch Diameter Cylinders and Two 11-Inch Diameter Interacting Uranium (93.2) Metal Cylinders

HEU-MET-FAST-059 Oralloy (93.15 235U) Metal Annuli With Beryllium Core

HEU-MET-FAST-061 Oralloy (93.2 235U) Metal Cylinder With Beryllium Top Reflector

HEU-MET-FAST-071 Uranium (93.14) Metal Annuli With One- And Two-Inch Graphite Reflectors

HEU-MET-FAST-074 Oralloy (93.2 235U) Bare Metal Annuli and Disks

HEU-MET-FAST-076 Uranium (93.14 235U) Metal Annuli and Cylinders with Thick Polyethylene Reflectors and/or Internal Polyethylene Moderator

HEU-MET-FAST-077 Experiments with HEU (93.14 Wt. \%) Metal Annuli with Internal Graphite Cylinder

HEU-MET-FAST-081 Grotesque: Complex Geometric Arrangement of Unreflected HEU (93.15) Metal

HEU-MET-FAST-083 Complex Geometry Bare Oralloy (93.15 235U) Metal Annuli Experiments

HEU-MET-FAST-096 Static Critical Experiments For The Sorgente Rapida (Sora) Reactor Mockup

HEU-MET-FAST-099 Fast Neutron Spectrum Potassium Worth for Space Power Reactor Design Validation (also known as ORCEF-SPACE-EXP-001)

HEU-MET-FAST-100 Orsphere: Critical, Bare, HEU (93.2)-Metal Sphere

SUB-HEU-Sol-THERM-001 Unreflected high-enriched uranyl nitrate subcritical noise measurements-draining tank

SUB-HEU-SOL-THERM-002 Subcritical noise measurements for two coaxial cylindrical tanks containing $93.1 \%$ uranyl nitrate solution

SCCA-SPACE-EXP-001 Critical configuration and physics measurements for assemblies of $\mathrm{U}(93.15) \mathrm{O}_{2}$ fuel rods 
SCCA-SPACE-EXP-002 Critical configuration and physics measurements for assemblies of $\mathrm{U}(93.15) \mathrm{O}_{2}$ fuel rods $(1.506-\mathrm{cm}$ pitch)

SCCA-SPACE-EXP-003 Critical configuration and physics measurements for beryllium reflected assemblies of $\mathrm{U}(93.15) \mathrm{O}_{2}$ fuel rods (1.506-cm pitch and 7-tube clusters) 


\section{APPENDIX B UNCERTAINTIES IN MATERIALS PROVIDED BY THE Y-12 NSC}

The uncertainties in the masses, dimension, and uranium isotopics measured at the Y-12 NSC are discussed in the following reference.

John Mihalczo, Uncertainties in Masses, Dimensions, Impurities, and Isotopics of HEU Metal Used in Critical Experiments at ORCEF, ORNL Report, ORNL/TM-2012/32 (September 2012). [OSTI \#1052246]

Some recently discovered data from Y-12 NSC inspection reports for HEU metal parts are given in the following table. For some parts only, two results were available. The data in this appendix are the results of individual measurements of these quantities. The mass for each part was measured three times; the dimensions were measured at three different locations for each part; the uranium isotopics were measured usually by dividing a metal chip from the machining process into thirds and performing isotopic analysis on each third. These data are not available for all parts, and for some parts, only two results are presented. The masses measured were rounded to grams, and in no case for these 37 parts did the mass differ for the three individual measurements. The heights given in the table were all measured to one-tenth of a thousandth, but zeros after the decimal are not listed in the table. For example, where the entry of the table is given as 1.5, the measured value was $1.5000 \mathrm{in}$. The height measured at three different locations on the parts to $\pm 0.0001 \mathrm{in}$. was the same at all locations for all but one of 37 parts. Thus, the heights are known to half of a ten thousandth of an inch.

The inside diameters for the three measurements for each individual part were identical except for three of the 37 parts. In two cases they differed by 0.00005 in. and in the other case by $0.0001 \mathrm{in}$. The outside diameters for the three measurements for each individual part were identical except for six of the 37 parts, where they differed by 0.00005 in.

The isotopic enrichments are measured to $0.01 \mathrm{wt} . \%$ and thus are known to $\pm 0.005 \mathrm{wt}$. \%. The wt. $\%{ }^{235} \mathrm{U}$ for the three measurements for each individual part was identical except for one of the 37 parts, where it differed by 0.02 wt. $\%$. The wt. $\%{ }^{234} \mathrm{U}$ for the three measurements for each individual part was identical for all 37 parts. The wt. $\%{ }^{234} U$ for the three measurements for each individual part was identical except for three of the 37 parts, where it differed by $0.02 \mathrm{wt} \%$ for two parts and 0.05 mwt. \% for the other.

Measured mass (g), dimension (in.), and uranium isotopics (wt. \%) from inspection reports

\begin{tabular}{llllllllll}
\hline & Part & Mass & Height & ID & OD & U-235 & U-234 & U-236 & U-238 \\
\hline HMF051 & 2735 & 13409 & 0.9985 & 13.002 & 14.9935 & 93.12 & 0.98 & 0.25 & 5.65 \\
HMF071 & & 13409 & 0.9985 & 13.002 & 14.9935 & 93.12 & 0.98 & 0.25 & 5.65 \\
HMF076 & & 13409 & 0.9985 & 13.002 & 14.9935 & 93.12 & 0.98 & 0.25 & 5.65 \\
HMF051 & 2736 & 2895 & 0.37635 & 7.0026 & 8.996 & 93.17 & 1.01 & 0.21 & 5.61 \\
HMF071 & & 2895 & 0.37635 & 7.0026 & 8.996 & 93.17 & 1.01 & 0.21 & 5.61 \\
HMF076 & & 2895 & 0.37635 & 7.0026 & 8.996 & 93.17 & 1.01 & 0.21 & 5.61 \\
HMF051 & 2737 & 4336 & 0.5625 & 7.0015 & 8.9965 & 93.08 & 0.99 & 0.29 & 5.64 \\
HMF071 & & 4336 & 0.5625 & 7.0015 & 8.9965 & 93.08 & 0.99 & 0.29 & 5.64 \\
HMF076 & & 4336 & 0.5625 & 7.0015 & 8.9965 & 93.08 & 0.99 & 0.29 & 5.64
\end{tabular}




\begin{tabular}{|c|c|c|c|c|c|c|c|c|c|}
\hline & Part & Mass & Height & ID & OD & U-235 & U-234 & U-236 & U-238 \\
\hline HMF051 & 2738 & 7710 & 1.0012 & 7.00375 & 8.99575 & 93.15 & 0.98 & 0.24 & 5.63 \\
\hline HMF071 & & 7710 & 1.0012 & 7.00375 & 8.99575 & 93.15 & 0.98 & 0.24 & 5.63 \\
\hline HMF076 & & 7710 & 1.0012 & 7.00375 & 8.99575 & 93.15 & 0.98 & 0.24 & 5.63 \\
\hline HMF051 & 2739 & 13461 & 0.9945 & 13.0027 & 14.9955 & 93.16 & 0.96 & 0.25 & 5.63 \\
\hline HMF071 & & 13461 & 0.9945 & 13.00265 & 14.9955 & 93.16 & 0.96 & 0.25 & 5.63 \\
\hline HMF076 & & 13461 & 0.9945 & 13.0027 & 14.9955 & 93.16 & 0.96 & 0.25 & 5.63 \\
\hline HMF051 & 2740 & 11568 & 1.5 & 7.0025 & 8.99625 & 93.17 & 0.97 & 0.24 & 5.62 \\
\hline HMF071 & & 11568 & 1.5 & 7.0025 & 8.99625 & 93.17 & 0.97 & 0.24 & 5.62 \\
\hline HMF076 & & 11568 & 1.5 & 7.0025 & 8.99625 & 93.17 & 0.97 & 0.24 & 5.62 \\
\hline HMF051 & 2742 & 3617 & 0.3751 & 9.0015 & 10.9968 & 93.14 & 0.98 & 0.23 & 5.65 \\
\hline HMF071 & & 3617 & 0.3751 & 9.0015 & 10.99675 & 93.14 & 0.98 & 0.23 & 5.65 \\
\hline HMF076 & & 3617 & 0.3751 & 9.0015 & 10.9968 & 93.14 & 0.98 & 0.23 & 5.65 \\
\hline HMF051 & 2743 & 3621 & 0.374 & 9.0025 & 10.9965 & 93.14 & 0.98 & 0.23 & 5.65 \\
\hline HMF071 & & 3621 & 0.374 & 9.0025 & 10.9965 & 93.14 & 0.98 & 0.23 & 5.65 \\
\hline HMF076 & & 3621 & 0.374 & 9.0025 & 10.9965 & 93.14 & 0.98 & 0.23 & 5.65 \\
\hline HMF051 & 2744 & 1223 & 0.12675 & 9.0065 & 10.9968 & 93.14 & 0.98 & 0.23 & 5.65 \\
\hline HMF071 & & 1223 & 0.12675 & 9.0065 & 10.99675 & 93.14 & 0.98 & 0.23 & 5.65 \\
\hline HMF076 & & 1223 & 0.12675 & 9.0065 & 10.9968 & 93.14 & 0.98 & 0.23 & 5.65 \\
\hline HMF051 & 2745 & 9634 & 0.999 & 9.001 & 10.9965 & 93.2 & 0.96 & 0.22 & 5.62 \\
\hline HMF071 & & 9634 & 0.999 & 9.001 & 10.9965 & 93.2 & 0.96 & 0.22 & 5.62 \\
\hline HMF076 & & 9634 & 0.999 & 9.001 & 10.9965 & 93.2 & 0.96 & 0.22 & 5.62 \\
\hline HMF051 & 2746 & 1238 & 0.12865 & 9.00175 & 10.9965 & 93.09 & 1 & 0.22 & 5.69 \\
\hline HMF071 & & 1238 & 0.12865 & 9.00175 & 10.9965 & 93.09 & 1 & 0.22 & 5.69 \\
\hline HMF076 & & 1238 & 0.12865 & 9.00175 & 10.9965 & 93.09 & 1 & 0.22 & 5.69 \\
\hline HMF051 & 2747 & 14436 & 1.4999 & 9.002 & 10.9968 & 93.16 & 0.98 & 0.19 & 5.67 \\
\hline HMF071 & & 14436 & 1.4999 & 9.002 & 10.99675 & 93.16 & 0.98 & 0.19 & 5.67 \\
\hline HMF076 & & 14436 & 1.4999 & 9.002 & 10.9968 & 93.16 & 0.98 & 0.19 & 5.67 \\
\hline HMF051 & 2748 & 14462 & 1.5 & 9.0025 & 10.9975 & 93.09 & 1 & 0.22 & 5.69 \\
\hline HMF071 & & 14462 & 1.5 & 9.0025 & 10.9975 & 93.09 & 1 & 0.22 & 5.69 \\
\hline HMF076 & & 14462 & 1.5 & 9.0025 & 10.9975 & 93.09 & 1 & 0.22 & 5.69 \\
\hline HMF051 & 2749 & 4360 & 0.3774 & 11.003 & 12.9955 & 93.19 & 0.98 & 0.25 & 5.58 \\
\hline HMF071 & & 4360 & 0.3774 & 11.003 & 12.9955 & 93.19 & 0.98 & 0.25 & 5.58 \\
\hline HMF076 & & 4360 & 0.3774 & 11.003 & 12.9955 & 93.19 & 0.98 & 0.25 & 5.58 \\
\hline HMF051 & 2750 & 4336 & 0.37545 & 11.0015 & 12.9945 & 93.12 & 0.95 & 0.25 & 5.68 \\
\hline HMF071 & & 4336 & 0.37545 & 11.0015 & 12.9945 & 93.12 & 0.95 & 0.25 & 5.68 \\
\hline HMF076 & & 4336 & 0.37545 & 11.0015 & 12.9945 & 93.12 & 0.95 & 0.25 & 5.68 \\
\hline HMF051 & 2751 & 5822 & 0.50355 & 11.0015 & 12.9958 & 93.13 & 0.98 & 0.24 & 5.65 \\
\hline HMF071 & & 5822 & 0.50355 & 11.0015 & 12.99575 & 93.13 & 0.98 & 0.24 & 5.65 \\
\hline HMF076 & & 5822 & 0.50355 & 11.0015 & 12.9958 & 93.13 & 0.98 & 0.24 & 5.65 \\
\hline HMF051 & 2752 & & & & & & & & \\
\hline HMF071 & & 5811 & 0.50325 & 11.0025 & 12.9955 & 93.13 & 0.98 & 0.24 & 5.65 \\
\hline HMF076 & & 5811 & 0.50325 & 11.0025 & 12.9955 & 93.13 & 0.98 & 0.24 & 5.65 \\
\hline HMF051 & 2753 & & & & & & & & \\
\hline HMF071 & & 5782 & 0.5013 & 11.003 & 12.99675 & 93.12 & 0.95 & 0.25 & 5.69 \\
\hline HMF076 & & 5782 & 0.5013 & 11.003 & 12.99675 & 93.12 & 0.95 & 0.28 & 5.66 \\
\hline HMF051 & 2754 & 5826 & 0.5036 & 11.004 & 12.9953 & 93.1 & 0.96 & 0.28 & 5.66 \\
\hline HMF071 & & 5826 & 0.5036 & 11.004 & 12.9953 & 93.1 & 0.96 & 0.28 & 5.66 \\
\hline HMF076 & & 5826 & 0.5036 & 11.004 & 12.9953 & 93.1 & 0.96 & 0.28 & 5.66 \\
\hline
\end{tabular}




\begin{tabular}{|c|c|c|c|c|c|c|c|c|c|}
\hline & Part & Mass & Height & ID & OD & U-235 & U-234 & U-236 & U-238 \\
\hline HMF051 & 2755 & 6514 & 0.5635 & 11.003 & 12.996 & 93.1 & 0.96 & 0.28 & 5.66 \\
\hline HMF071 & & 6514 & 0.5635 & 11.003 & 12.99595 & 93.1 & 0.96 & 0.28 & 5.66 \\
\hline HMF076 & & 6514 & 0.5635 & 11.003 & 12.996 & 93.1 & 0.96 & 0.28 & 5.66 \\
\hline HMF051 & 2756 & 11567 & 1.0002 & 11.0036 & 12.9967 & 93.18 & 0.93 & 0.25 & 5.64 \\
\hline HMF071 & & 11567 & 1.0002 & 11.0036 & 12.9967 & 93.18 & 0.93 & 0.25 & 5.64 \\
\hline HMF076 & & 11567 & 1.0002 & 11.0036 & 12.9967 & 93.18 & 0.93 & 0.25 & 5.64 \\
\hline HMF051 & 2757 & 11575 & 1.00155 & 11.0025 & 12.996 & 93.2 & 0.96 & 0.23 & 5.61 \\
\hline HMF071 & & 11575 & 1.00155 & 11.0025 & 12.996 & 93.2 & 0.96 & 0.23 & 5.61 \\
\hline HMF076 & & 11575 & 1.00155 & 11.0025 & 12.996 & 93.2 & 0.96 & 0.23 & 5.61 \\
\hline HMF051 & 2761 & & & & & & & & \\
\hline HMF071 & & 1706 & 0.1265 & 13.001 & 14.99475 & 93.12 & 0.96 & 0.27 & 5.65 \\
\hline HMF076 & & 1706 & 0.1265 & 13.001 & 14.99475 & 93.12 & 0.96 & 0.27 & 5.65 \\
\hline HMF051 & 2762 & 7703 & 0.99925 & 7.00375 & 8.99625 & 93.13 & 0.97 & 0.27 & 5.63 \\
\hline HMF071 & & 7703 & 0.99925 & 7.0037 & 8.99625 & 93.13 & 0.97 & 0.27 & 5.63 \\
\hline HMF076 & & 7703 & 0.99925 & 7.00375 & 8.99625 & 93.13 & 0.97 & 0.27 & 5.63 \\
\hline HMF051 & 2763 & 953 & 0.1243 & 7.0038 & 8.9958 & 93.18 & 0.96 & 0.25 & 5.66 \\
\hline HMF071 & & 953 & 0.1243 & 7.0038 & 8.9958 & 93.18 & 0.96 & 0.25 & 5.61 \\
\hline HMF076 & & 953 & 0.1243 & 7.0038 & 8.9958 & 93.18 & 0.96 & 0.25 & 5.61 \\
\hline HMF051 & 2766 & 7605 & 0.563 & 13.001 & 14.9965 & 93.16 & 0.98 & 0.27 & 5.59 \\
\hline HMF071 & & 7605 & 0.563 & 13.001 & 14.9965 & 93.16 & 0.98 & 0.27 & 5.59 \\
\hline HMF076 & & 7605 & 0.563 & 13.001 & 14.9965 & 93.16 & 0.98 & 0.27 & 5.59 \\
\hline HMF051 & 2773 & 962 & 0.125 & 7.0015 & 8.997 & 93.17 & 0.97 & 0.24 & 5.62 \\
\hline HMF071 & & 962 & 0.126 & 7.0015 & 8.997 & 93.17 & 0.97 & 0.24 & 5.62 \\
\hline HMF076 & & 962 & 0.126 & 7.0015 & 8.997 & 93.17 & 0.97 & 0.24 & 5.62 \\
\hline HMF051 & 2774 & 1930 & 0.25 & 7.003 & 8.9965 & 93.08 & 0.99 & 0.24 & 5.69 \\
\hline HMF071 & & 1930 & 0.25 & 7.003 & 8.9965 & 93.08 & 0.99 & 0.29 & 5.64 \\
\hline HMF076 & & 1930 & 0.25 & 7.003 & 8.9965 & 93.08 & 0.99 & 0.29 & 5.64 \\
\hline HMF051 & 2775 & 1917 & 0.2485 & 7.004 & 8.99675 & 93.15 & 0.98 & 0.24 & 5.63 \\
\hline HMF071 & & 1917 & 0.2485 & 7.004 & 8.99675 & 93.15 & 0.98 & 0.24 & 5.63 \\
\hline HMF076 & & 1917 & 0.2485 & 7.004 & 8.99675 & 93.15 & 0.98 & 0.24 & 5.63 \\
\hline HMF051 & 2776 & 9644 & 1.0015 & 9.0015 & 10.9965 & 93.16 & 0.96 & 0.23 & 5.65 \\
\hline HMF071 & & 9644 & 1.0015 & 9.0015 & 10.9965 & 93.16 & 0.96 & 0.23 & 5.65 \\
\hline HMF076 & & 9644 & 1.0015 & 9.0015 & 10.9965 & 93.16 & 0.96 & 0.23 & 5.65 \\
\hline HMF051 & 2778 & 2411 & 0.251 & 9.002 & 10.9965 & 93.16 & 0.96 & 0.23 & 5.65 \\
\hline HMF071 & & 2411 & 0.251 & 9.002 & 10.9965 & 93.16 & 0.96 & 0.23 & 5.65 \\
\hline HMF076 & & 2411 & 0.251 & 9.002 & 10.9965 & 93.16 & 0.96 & 0.23 & 5.65 \\
\hline HMF051 & 2779 & 2417 & 0.251 & 9.0015 & 10.997 & 93.16 & 0.96 & 0.23 & 5.65 \\
\hline HMF071 & & 2417 & 0.251 & 9.0015 & 10.997 & 93.16 & 0.96 & 0.23 & 5.65 \\
\hline HMF076 & & 2417 & 0.251 & 9.0015 & 10.997 & 93.16 & 0.96 & 0.23 & 5.65 \\
\hline HMF051 & 2780 -- & & & & & & & & \\
\hline HMF071 & & 1440 & 0.12485 & 11.002 & 12.99605 & 93.13 & 0.98 & 0.25 & 5.64 \\
\hline HMF076 & & 1440 & 0.12485 & 11.002 & 12.99605 & 93.13 & 0.98 & 0.25 & 5.64 \\
\hline HMF071 & 2784 & 5039 & 0.3725 & 13.0015 & 14.9945 & 93.13 & 0.99 & 0.24 & 5.64 \\
\hline HMF076 & & 5039 & 0.3725 & 13.0015 & 14.9945 & 93.11 & 0.99 & 0.26 & 5.64 \\
\hline HMF051 & 2785 & 5043 & 0.3747 & 13.0029 & 14.9958 & 93.14 & 0.98 & 0.24 & 5.64 \\
\hline HMF071 & & 5043 & 0.3747 & 13.00285 & 14.99575 & 93.11 & 0.99 & 0.26 & 5.64 \\
\hline HMF076 & & 5043 & 0.3747 & 13.0029 & 14.9958 & 93.14 & 0.98 & 0.24 & 5.64 \\
\hline HMF051 & 2829 & 2895 & 0.37625 & 7.00315 & 8.99625 & 93.1 & 0.99 & 0.24 & 5.67 \\
\hline
\end{tabular}




\begin{tabular}{llllllllll}
\hline & Part & Mass & Height & ID & OD & U-235 & U-234 & U-236 & U-238 \\
\hline HMF071 & & 2895 & 0.37625 & 7.00315 & 8.99625 & 93.1 & 0.99 & 0.24 & 5.67 \\
HMF076 & & 2895 & 0.37625 & 7.00315 & 8.99625 & 93.1 & 0.99 & 0.24 & 5.67 \\
HMF051 & 2848 & 6748 & 0.5019 & 13.0031 & 14.9964 & 93.18 & 0.99 & 0.24 & 5.66 \\
HMF071 & & 6748 & 0.5019 & 13.0031 & 14.9964 & 93.18 & 0.99 & 0.24 & 5.59 \\
HMF076 & & 6748 & 0.5019 & 13.0031 & 14.9964 & 93.18 & 0.99 & 0.24 & 5.59 \\
\hline
\end{tabular}

